\title{
A Review of the Tetrapod Track Record in China, with Special Reference to Type Ichnospecies: Implications for Ichnotaxonomy and Paleobiology
}

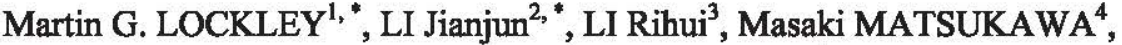 \\ Jerald D. HARRIS ${ }^{5}$ and XING Lida ${ }^{6}$
}

1 University of Colorado Denver, Dinosaur Tracks Research Group, P.O. Box 173364, Campus Box 172, Denver, CO 80217-3364, USA

2 Beijing Museum of Natural History Museum, 126 Tianqiao, South Street, Beijing 100050, China

3 Qingdao Institute of Marine Geology, China Geological Survey, 62 Fuzhou Road, Qingdao 266071, China

4 Department of Environmental Sciences, Tokyo Gakugei University, Koganei, Tokyo, 184-8501, Japan

5 Department of Physical Sciences, Dixie State College, 225 South 700 East, St. George, Utah 84770

6 Department of Biological Sciences, University of Alberta, 11455 Saskatchewan Drive, Edmonton, Alberta T6G 2E9, Canada

\begin{abstract}
Splitting" and "lumping" are perpetual problems in vertebrate, especially dinosaur, ichnotaxonomy. Chinese dinosaur ichnotaxonomy, which began in 1940, provides a series of interesting case studies, highlighting the dual problems of historical and dubious ichnotaxonomy. Chinese Mesozoic tetrapod track types have been placed into 63 ichnospecies (one Triassic, 28 Jurassic, and 34 Cretaceous), exclusive of other, non-type ichnospecies or ichnotaxa identified from China. Fifty-two $(\sim 83 \%)$ of these 63 tetrapod ichnospecies were placed in monospecific ichnogenera. At the ichnogenus level, we prune-either by recognizing nomina dubia or by synonymy -17 from the list of 53 dinosaurian ichnogenera (a $32 \%$ reduction), leaving 36 ichnotaxa that we consider valid. Most of the cuts affect Jurassic theropod ichnotaxa, which are reduced from 23 to only nine because most ichnogenera are subjective junior synonyms of Grallator and Eubrontes. Fewer Chinese Cretaceous ichnotaxa (only six of $\mathbf{2 1}$ ichnogenera) are obvious nomina dubia or subjective synonyms, suggesting greater east Asian endemism during this time. Because ichnospecies differences are subtle, we provisionally retain ichnospecies as valid pending detailed comparative analyses of congeneric ichnospecies. This synthesis is long overdue and is necessary to address problems of historical and provincial ichnotaxonomy, which severely hamper comparisons of tetrapod ichnofaunas in space and time.
\end{abstract}

Key words: Dinosaurs, birds, theropods, ichnotaxonomy, Mesozoic, China

\section{Introduction}

"Splitting" and "lumping" are perennial problems in vertebrate ichnotaxonomy, particularly in dinosaur ichnotaxonomy. Much splitting has been due to provincial taxonomy: assigning new names to footprint morphologies simply because they come from new areas, localities, and/ or formations, and without comparison to similar tracks from other areas and/or time periods. Their novelties in terms of geographic and geological occurrences, rather than any unique morphologies, were used improperly to

*Corresponding author. E-mail: Martin.Lockley@UCDenver.edu 1jj5681@126.com justify erecting new ichnotaxa-in short, newness of occurrence does not equate to newness of ichnotaxonomy. Except when the specimens on which the ichnotaxa were based differ markedly in morphology, most ichnologists would subjectively regard most as subjective junior synonyms of ichnospecies named previously from other areas, localities, and/or formations, despite the fact that the Chinese specimens were based on new occurrences. In some cases, such provincial taxonomies are residuals of history, resulting from the publication of ichnotaxonomic descriptions in literature that was, at this time, poorly distributed; often these are regional publications in various languages. Such sources were often unknown, unavailable, 
or inaccessible to many authors describing new specimens, limiting proper comparisons between ichnotaxa and perhaps falsely leading to the perception that new specimens were morphologically unique. Other ichnotaxa (nomina dubia) were based on poorly preserved ichnites that lack adequate diagnostic morphologies and/or involve extramorphological features and therefore do not accurately reflect true pedal morphologies.

Between 1940 and 2012, a total of 63 tetrapod ichnospecies were erected based on Chinese type specimens (Table 1). All are Mesozoic in age; all but a single Triassic type are either Jurassic (28) or Cretaceous (34) in age. Except for one crocodylian and two presumed ornithischian dinosaur ichnospecies, all of the Jurassic ichnotaxa have been attributed to theropod dinosaurs. Similarly, only two of the Cretaceous ichnospecies are non-dinosaurian (one pterosaur and one crocodylian), although unlike in the Jurassic, seven pertain to avian theropods (birds). Among the 25 inferred non-avian dinosaurian ichnospecies, 18 have been attributed to theropods, four to ornithopods, two to sauropods, and one, incorrectly, to an ankylosaur.

The primary goal of this paper is to discuss the validity of Mesozoic tetrapod ichnotaxa that are based on Chinese type ichnospecies. Many of these have been previously treated as nomina dubia or otherwise had their validities questioned, either formally or informally. For historical reasons, including the aforementioned inaccessibility of relevant literature - a significant problem because of language barriers, academic traditions, and/or limitations of publication distribution-a number of ichnotaxa constitute obvious or suspected subjective synonyms. Certainly, the over-splitting of vertebrate ichnotaxa is by no means a provincial phenomenon restricted to any one particular research tradition or historical chapter in science: the father of ichnology himself (Hitchcock, 1858) was responsible for naming many ichnotaxa that, according to many researchers (e.g., Olsen, 1980; Gierliński, 1994; Rainforth, 2005), include many synonyms. However, revising the extensive work of Hitchcock and of Early Jurassic tracks from eastern and northeastern USA, in order to unequivocally remove invalid or otherwise dubious ichnotaxa, has proved difficult (Olsen et al., 1998). While we are aware of the tendency to over-split that arises from research with a provincial focus and/or limited access to relevant literature, we attempt to avoid the altemate approach of lumping ichnospecies without careful study of the type material, its state of preservation, and the quality of the primary literature.

For these reasons, herein we cannot tackle the monumental task of evaluating every ichnotype for its validity at the ichnospecies level. However, working at the more general ichnogenus level (Lucas, 2007) has precedents, and we therefore attempt to evaluate the validity of all of the relevant ichnogenera. Therefore, while we transfer many ichnospecies into appropriate ichnogenera, we have not proposed synonymies at the ichnospecies level. This preserves the complete list of Chinese type ichnospecies as a reference catalog, and leaves open the possibility of further analyses of type ichnospecies and their relations at the "ichnospecies level." Nevertheless, in the sections that follow, we discuss all named Chinese tetrapod ichnospecies in order to objectively assess their validities and where they are best accommodated at the ichnogenus level.

An additional consideration involves the dating of type localities and type specimens (reviewed for the Cretaceous by Matsukawa et al. [2006] and Chen et al. [2006]). The inferred ages of several Chinese sites and specimens are uncertain and, in some cases, have changed over time. While such changes and uncertainty may compromise biostratigraphic comparisons of Chinese tracks with those from other areas, in principle it does not affect evaluation of the ichnotaxonomic validities of specimens themselves based on comparative morphology, analysis of preservation, and the accuracy and quality of primary sources.

Bearing in mind that a few ichnotaxa reported from China are not endemic (i.e., they are based on type materials from other countries), the composition of the list of Chinese type specimens does not accurately reflect the diversity of Chinese track types or inferred track makers, even after we have pruned out inappropriately named ichnotaxa. Stated another way, to accurately understand the complete Chinese track record, other recorded ichnotaxa must be added (see below) and obvious synonyms must be subtracted. Thus, on the one hand, the list of Chinese type ichnospecies discussed herein reflects the history of vertebrate track research in China combined with ichnotaxonomic traditions, geography, and the distribution of track-bearing strata in China. On the other hand, comparison of Chinese tracks to ichnotaxa named elsewhere, as well as additions and amendments to Chinese ichnotaxonomy (especially synonymies), facilitate perception of how the Chinese track record fits into global ichnotaxonomic trends.

\section{Ichnotaxonomy}

In this section, we review known ichnotaxa to assess whether any are adequately described and/or differentiable from existing ichnospecies, and therefore accommodated in an appropriate ichnogenus. In cases where tracks are so 
Table 1 Tetrapod type ichnospecies from China named between 1940 and 2012. Ichnospecies (numbered 1-63) are listed first by age (period and epoch) and second by order of publication

\begin{tabular}{|c|c|c|c|}
\hline Time Period & $\#$ & Ichnotaxon & Ichnospecies Establizhed by \\
\hline $\begin{array}{l}\text { Triassic } \\
\text { (1 isp. in } 1 \text { igen.) }\end{array}$ & 1 & Pengxianpus cifengensis & Yang and Yang, 1987 \\
\hline 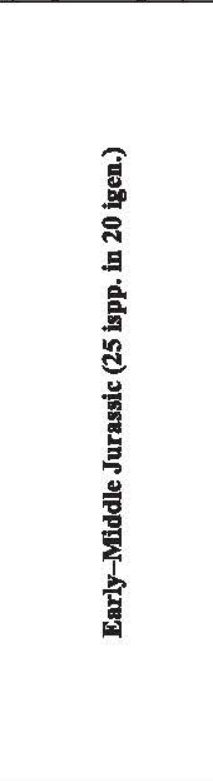 & $\begin{array}{l}2 \\
3 \\
4 \\
5 \\
6 \\
7 \\
8 \\
9 \\
10 \\
11 \\
12 \\
13 \\
14 \\
15 \\
16 \\
17 \\
18 \\
19 \\
20 \\
21 \\
22 \\
23 \\
24 \\
25 \\
26\end{array}$ & $\begin{array}{l}\text { Kuangyuanpus szechuanensis (crocodylian) } \\
\text { Sinoichnites youngi (ornithischian) } \\
\text { Changpelpus carbonicus } \\
\text { Shensipus tungchuanghensis } \\
\text { Changpeipus luanpingeris } \\
\text { Grallator limnosus } \\
\text { Paracoelunosaurichnus monax } \\
\text { Schizograllator xiaohebaensis } \\
\text { Youngichnus xiyangensis } \\
\text { Zhengichnus jinningensis } \\
\text { Zizhongpus wumanensis } \\
\text { Chongqingpus microiscus } \\
\text { Chongqingpus nananensis } \\
\text { Chongqingpus yemiaoxiensis } \\
\text { Tuojiangpus shuinanensis } \\
\text { Chonglongpus hel } \\
\text { Megaichnites jizhaishlensis } \\
\text { Jinlijingpus nianpanshanensis } \\
\text { Chuanchengpus wuhaungensis } \\
\text { Lufengopus dongi } \\
\text { Changpeipus xuiana } \\
\text { Weiyuanpus zigongensis } \\
\text { Changpeipus pareschequier } \\
\text { Kayentapus hailiutuensis } \\
\text { Shenmulchnus youngteilhardorum(ornithischian) }\end{array}$ & 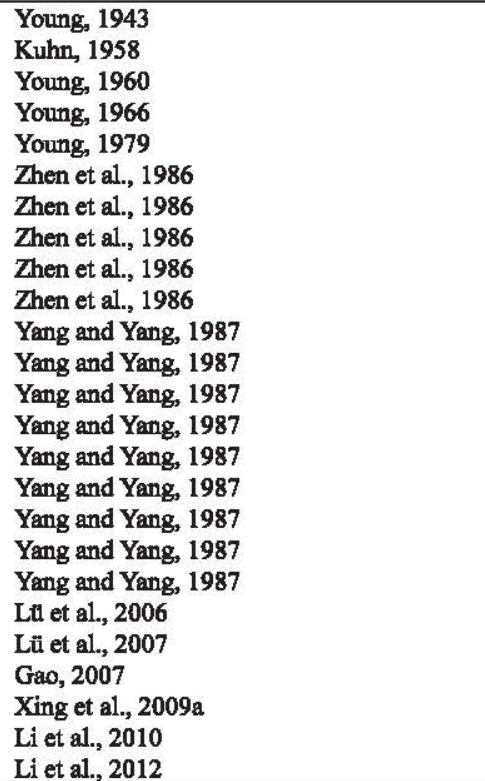 \\
\hline $\begin{array}{l}\text { Late Jurassic } \\
\text { (3 ispp. in } 3 \text { igen.) }\end{array}$ & $\begin{array}{l}27 \\
28 \\
29\end{array}$ & $\begin{array}{l}\text { Yangtzepus yipingensis } \\
\text { Jialingpus yuechiensis } \\
\text { Huanglongpus shengouensis }\end{array}$ & $\begin{array}{l}\text { Young, } 1960 \\
\text { Zhen et al., } 1983 \\
\text { Yang and Yang, } 1987\end{array}$ \\
\hline 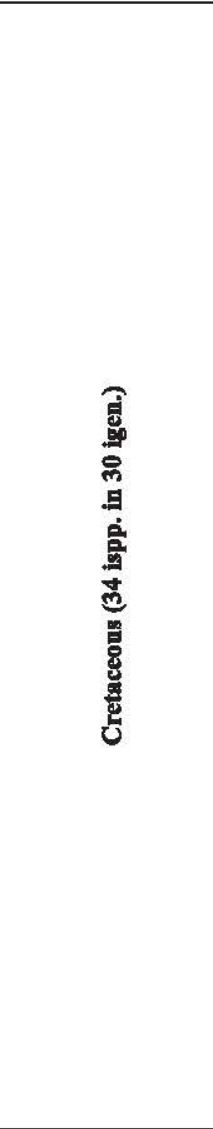 & $\begin{array}{l}43 \\
44 \\
45 \\
46 \\
47 \\
48 \\
49 \\
50 \\
51 \\
52 \\
53 \\
54 \\
55 \\
56 \\
57 \\
58 \\
59 \\
60 \\
61 \\
62 \\
63\end{array}$ & 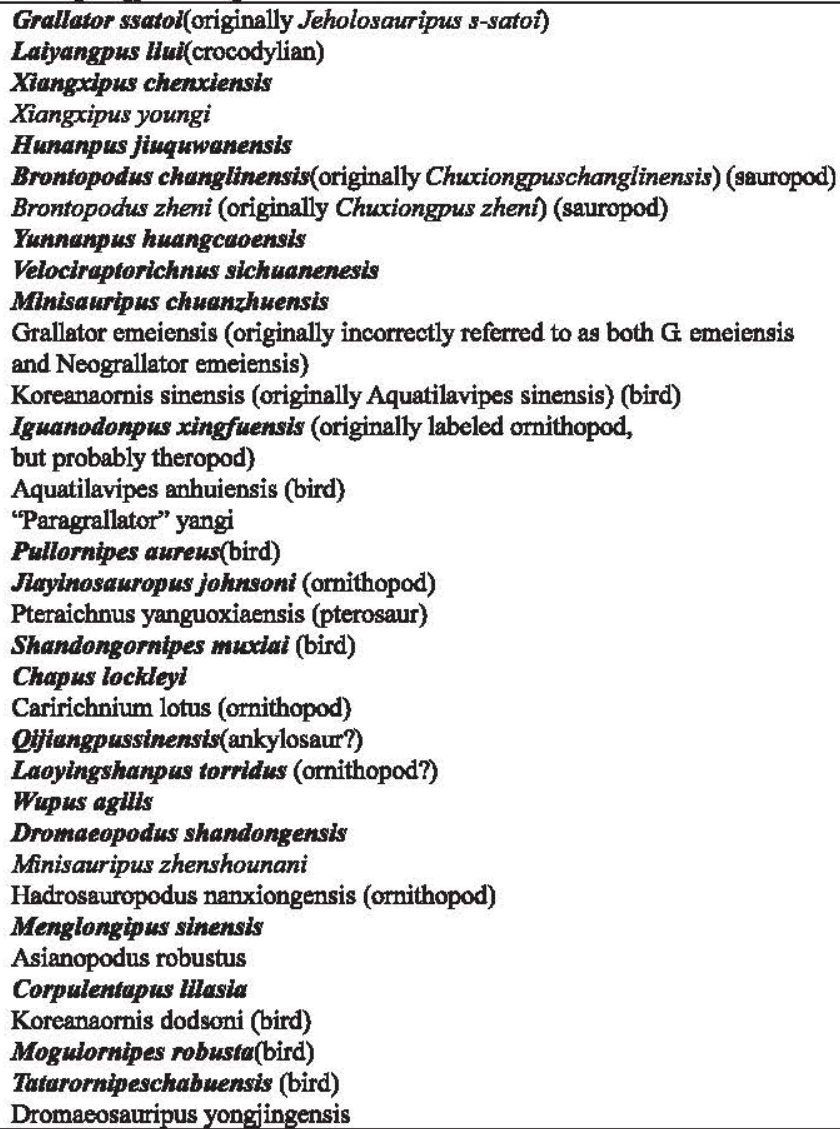 & $\begin{array}{l}\text { Yabe et al., 1940; Zhen et al., } 1989 \\
\text { Young, 1960; Lockley et al., } 2010 \\
\text { Zeng, 1982a, b } \\
\text { Zeng, 1982a, b } \\
\text { Zeng, 1982a, b } \\
\text { Chen and Huang, 1993; Lockley et al., } 2002 \\
\text { Chen and Huang, 1993; Lockley et al., } 2002 \\
\text { Chen and Huang, 1993 } \\
\text { Zhen et al. 1994 } \\
\text { Zhen et al. 1994 } \\
\text { Zhen et al. 1994 } \\
\text { Then et al. 1994 } \\
\text { Zhen et al., 1996 } \\
\text { Jin and Yan, } 1994 \\
\text { Li and Zhang, 2000 } \\
\text { Lockley et al., 2006 } \\
\text { Dong et al., 2003 } \\
\text { Peng et al., 2004 } \\
\text { Li et al.,, 2005; Li et al., } 2007 \\
\text { Li et al., 2006 } \\
\text { Xing et al., 2007 } \\
\text { Xing et al., 2007 } \\
\text { Xing et al., 2007 } \\
\text { Xing et al., 2007 } \\
\text { Li et al., 2008 } \\
\text { Lockley et al., 2008 } \\
\text { Xing et al., 2009c } \\
\text { Xing et al., 2009b } \\
\text { Li et al.,, 2011b } \\
\text { Li et al., 2011b } \\
\text { Xing et al.,, 2011 } \\
\text { Xing et al., 2011 } \\
\text { Lockley et al., 2012 } \\
\text { Xing et al., 2012 }\end{array}$ \\
\hline
\end{tabular}

Bold italic print = original Chinese type (ichnogenotype). Regular italic print $=$ a subsequently named, new ichnospecies of an aforementioned ichnogenus originally named from China (eight examples). Small, Romanized (non-italic) print = new ichnospecies of an ichnogenus originally named outside of China (12 examples). Synonymies listed were recognized prior to the present analysis; synonymies proposed in this paper are not listed (see text for detail). All tracks pertain to theropods (unless otherwise stated in parentheses). 
poorly preserved, or so poorly described and documented as to be undiagnostic, we declare the ichnotaxa nomina dubia that should henceforth be abandoned. In cases where the material is better preserved, but appears synonymous with an existing ichnotaxon at the ichnogenus or ichnospecies level, we emend those ichnotaxa accordingly. In such cases, we state explicitly whether there are any legitimate grounds for differentiating the junior and senior synonyms, or refer to previously published analyses. Such procedures do not, however, prevent future researchers from conducting further analyses of the material to retest the validity of the ichnotaxonomies proposed herein.

\subsection{Triassic Ichnospecies}

Specimens assigned to the widespread ichnogenus Chirotherium have been reported from the Middle Triassic of Guizhou Province (Lil et al., 2004), but Pengxianpus cifengensis (Yang and Yang, 1987) is the only endemic or "type" tetrapod ichnospecies from the Chinese Triassic. We have examined the type specimen in the Chonqing Natural History Museum in Sichuan Province, which consists of two tridactyl tracks, evidently representing a single step by a single track maker (Matsukawa et al., 2006; Lockley and Matsukawa, 2009). The track is not tetradactyl as suggested by Yang and Yang (1987). The preservation of the tracks is good, especially of the first track in the sequence, which possesses localized skin impressions (Lockley and Matsukawa, 2009). Although large, tridactyl tracks of similar size have been reported elsewhere from the Late Triassic (Lucas et al., 2006) and the Jurassic, time periods in which Eubrontes is the most common large, tridactyl ichnotaxon (see below), $P$. cifengensis cannot be attributed to Eubrontes with any confidence because it lacks the asymmetry and pad configurations of that ichnogenus. Thus, we retain $P$. cifengensis as a valid ichnotaxon.

\subsection{Early and Middle Jurassic Ichnospecies}

Kuangyuanpus szechuanensis (Young, 1943) is the only presumed non-dinosaurian type ichnospecies reported from the Jurassic of China (Fig. 1). It was also the first tetrapod ichnospecies formally named from the Jurassic of China, and while it was briefly considered a synonym of Batrachopus (Zhen et al., 1989), more recently it has been re-examined and re-described in detail by Lockley et al. (2010), who considered it valid and of presumed crocodylian affinity. The specimen is well-preserved, displaying five sharp digit traces on the presumed manus and four on the pes. The tracks have sediment mounds behind them, suggesting that they are swim tracks. According to Lockley et al. (2010) all these features are diagnostic of crocodylian affinity, although not exclusively so.

All 27 presumed dinosaurian type ichnospecies from the Jurassic of China appear to pertain to theropods (Table 1). Of these, 24 are considered Early or Middle Jurassic in age; $14(-58 \%)$ of these were described in two studies conducted in the 1980s (Zhen et al., 1986; Yang and Yang, 1987). These tracks comprise what can be characterized as the Yunnan and Sichuan ichnofaunas, respectively. Lockley and Matsukawa (2009) compared the ichnotaxa in the Yunnan ichnofauna by illustrating them at the same scales (Fig. 2), concluding that they could all probably be referred to known ichnotaxa, such as Eubrontes and Grallator. Lockley et al. (2003) reached the same conclusion for the Sichuan ichnofauna. Furthermore, Gierliniski (1994) also suggested that these ichnofaunas are seriously oversplit. 


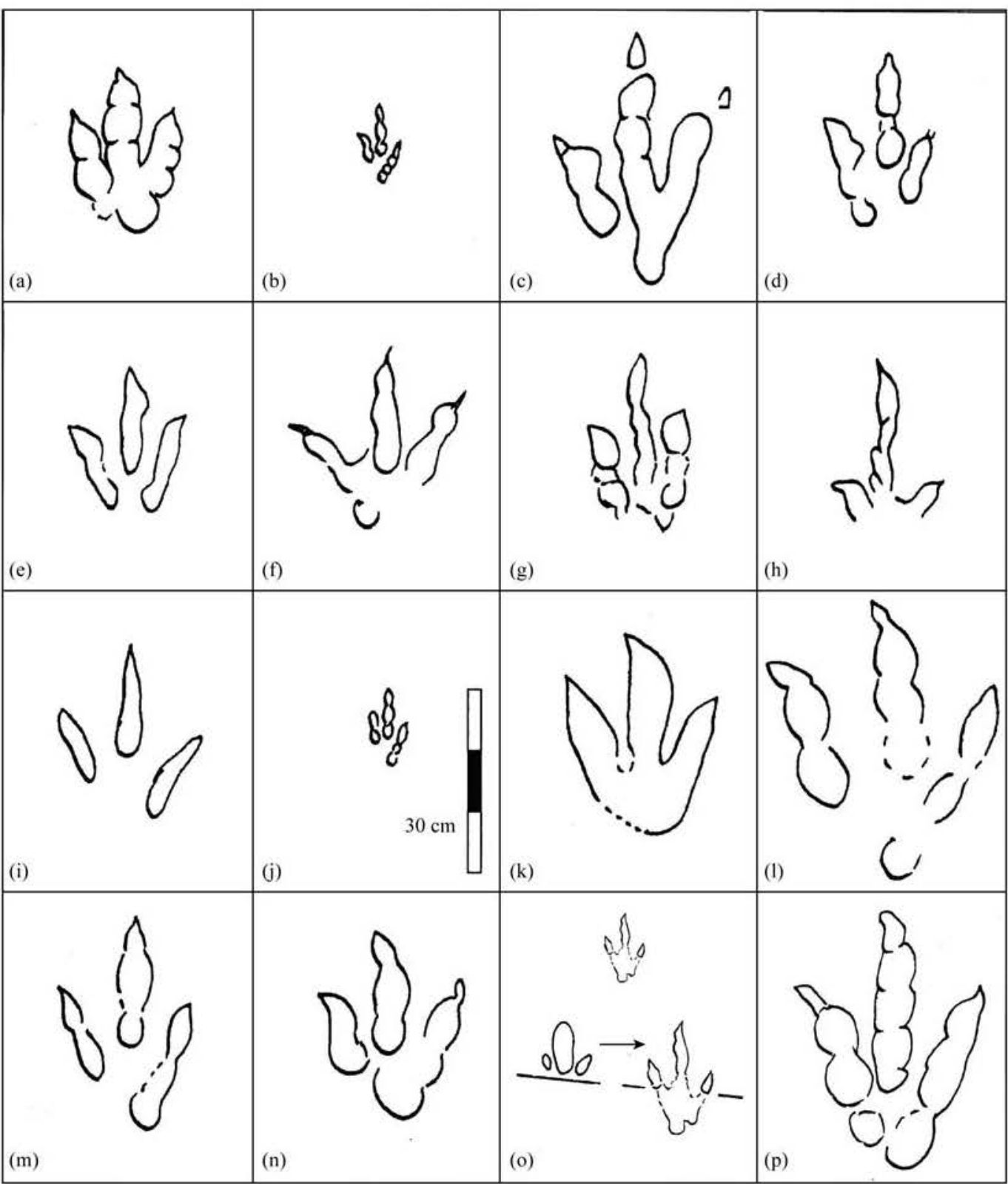

Fig. 2. Exemplar morphologies of the Early Jurassic theropod ichnotaxa Eubrontes Hitcheock 1845 (a) and Grallator Hitchcock 1858 (b) compared to various theropod tracks from the Lower Jurassic of China (o-p), arranged in chronological order of naming. (c), Changpeipus carbonicus; (d), Grallator limnasus; (e), Paracoelurosaurichnus monax; (f), Schizograllator xiaphebaensis; (g), Youngichnus xiyangensis; (h), Zhengichnus jimningensis. (i), Zizhongpus wumanensis; (j), Chongqingpus microiscus; (k), Tuojiangpus shuinanensis; (1), Chonglongpus hei; (m), Megaichnites jizhaoshiensis; (n), Jinliyingpus nianpanshanensis; (o), Chuanchengpus wuhuangensis, with correct outline (top) and enlargement (bottom) showing the differences between illustrations of the type (bottom left) and corrected illustration (bottom right); (p), Weiynaxpus zigongensis. All tracks (except for $i$ and $k$ ) drawn by the senior author from type material and redrafted to the same scale. $c$ after Young (1960); $d-h$ after Zhen et al. (1983); $i-0$ after Yang and Yang (1987).

Zhen et al. (1986) erected four monospecific ichnogenera from the Lower Jurassic Fengiiahe Formation of Jinning, Yunnan: Paracoelurosourichnus monax, Schizograllator xiaohebaensis, Youngichnus xiyangensis, and Zhengichnus jinningensis. In addition, they recognized a new ichnospecies of Grallator, G. limnosus, and the previously named ichnospecies Eubrontes platypus (Lull, 1904). The latter ichnospecies is not a Chinese type and so is not included in our lists (Table 1) and analyses. We have examined the type material of each of these ichnotaxa, which were originally illustrated with photos and line drawings. We also note that, at the time 
Table 2 Summary of ichnotaxonomic revisions of the six ichnospecies reported from the Lower Jurassic Fengjiahe Formation of Yunnan Province, China by Zhen et al. (1986)

\begin{tabular}{lll}
\hline Ichnotaxa of Zhen et al. (1986) & Revised Ichnotaxonomy & Comments \\
\hline Eubrontes platypus & no change & - \\
Grallator limnosus & no change & - \\
Paracoehrosaurichnus monax & Eubrontes monax comb. nov. & - \\
Schizograllator xiaohebaensis & Kayentapus xiaohebaensis comb. nov. & - \\
Youngichnus xiyangensis & Eubrontes xiyangensis comb. nov. & - \\
Zhengichnus jinningensis & nomen dubium & poor, undiagnostic preservation \\
\hline
\end{tabular}

Note that the original ichnogeneric diversity of six, mainly provincial, names is reduced to three ichnogenera that have global distributions. See text and Fig. 2 .

Table 3 Summary of ichnotaxonomic revisions of the nine ichnospecies reported from the Lower Jurassic Xintiangou and Lower Shaximiao formations of Sichuan Province, China by Yang and Yang (1987)

\begin{tabular}{llc}
\hline Ichnotaxa of Yang and Yang (1987) & Revised Ichnotaxonomy & Comments \\
\hline Zizhongpus wumanensis & Kayentapus wumaensis comb. nov. & poor, undiagnostic material \\
Tuojiangpus shuinanensis & nomen dubium & see Lockley et al. (2003) \\
Chonglongpus hei & Gigandipus hei & - \\
Megaichnites jizhaoshiensis & Kayentapus jizhaishiensis comb. nov. & - \\
Chuanchengpus wuhuangensis & Grallator wuhauangensis comb. nov. & - \\
Jinlijingpus nianpanshanensis & Eubrontes nianpanshanensis comb. nov. \\
Chongqingpus nananensis & Kayentapus nananensis comb. nov. & - \\
Chongqingpus yemiaoxiensis & Grallator yemiaoxiensis comb. nov. & - \\
Chonggingpus microiscus & Grallator microiscus comb. nov. & - \\
\hline
\end{tabular}

the original study was performed, comparative literature was difficult to obtain in China (implied in the acknowledgements in Zhen et al., 1986) and that the globally widespread Grallator- and Eubrontes-dominated, Early Jurassic ichnofauna (Olsen and Galton, 1984; Lucas, 2007; Lockley et al., 2011a, and references therein) was not widely recognized. Nevertheless, the authors clearly recognized affinities of some of their tracks to alreadyknown ichnotaxa (Coelurosaurichnus and Grallator, which formed the roots of two of their ichnogenus names). Perhaps unsurprisingly, the four ichnospecies not assigned to either Grallator and Eubrontes require comparison to ichnospecies of both of these ichnogenera, as well as to other, closely related forms (e.g., Kayentapus) named prior to the current renaissance in Chinese ichnology.

The G. limnosus, S. xiaohebaensis, and $Y$. xiyangensis types were based on trackways, whereas the other Yunnan ichnotaxa were based on individual tracks. We consider $Z$. jinningensis a nomen dubium because it is based on a poorly preserved specimen that is very distorted. $P$. monax and $Y$. xiyangensis are indistinguishable from Eubrontes at the ichnogenus level, they have the same digital pad formulae, and similar digit widths and divarication angles. Because no diagnostic features were given to distinguish either ichnospecies from type Eubrontes, or any other Eubrontes ichnospecies, the erection of the ichnogenera Paracoelurosaurichnus and Youngichnus were unjustified, and both are therefore assigned here to Eubrontes (Table 2). S. xiaohebaensis may be distinct from Eubrontes and has already been compared favorably with Kayentapus (Welles, 1971), both indirectly (Lockley and Hunt, 1995) and directly (Matsukawa et al., 2005; Lockley and Matsukawa, 2009; Lockley et al., 2011a). Thus, based on these previous suggestions of synonymy, we propose the combination $K$. ayentapus xiaohebaensis comb. nov. to accommodate these specimens. This implies that the Japanese ichnospecies Schizograllator otariensis becomes $K$. otariensis comb. nov., although the Japanese ichnospecies is smaller and more elongate than $K$. xiaohebaensis according to Matsukawa et al. (2005). As noted below, it is possible that Kayentapus is a subjective junior synonym of Changpeipus.

The Sichuan ichnofauna, from the Lower-Middle Jurassic Xintiangou Formation near Zizhou and Jinlijing, was described by Yang and Yang (1987), who erected the following monospecific ichnogenera: Zizhongpus wumanensis, Tuojiangpus shuinanensis, Chonglongpus hei, Megaichnites jizhaoshiensis, Chuanchengpus wuhuangensis, and Jinlijingpus nianpanshanensis. In addition, Yang and Yang (1987) erected three ichnospecies of the new ichnogenus Chongqingpus, $C$. microiscus, C. nananensis, and C. yemiaoxiensis, for tracksfrom a locality in the Lower Shaximiao Formation in Chongqing City. They also described Huanglongpus shengouensis from Upper Jurassic strata near Yuechi (see next section). Based on examination and re-illustration of most of the types, Lockley et al. (2003) and Lockley and Matsukawa (2009) commented on the similarities of these ichnospecies to Grallator, Eubrontes, and Kayentapus, to which they are herein referred (Table 3 ). In the case of Chongqingpus, C. microiscus, is assigned to Grallator microiscus comb. nov. and C. yemiaoxiensis is assigned to Grallator yemiaoxiensis comb. nov. (q.v. Lockley and Matsukawa, 2009). C. nananensis is assigned to Kayentapus nananensis comb. Nov. (Xing et al., in press).

Yang and Yang (1987) provided photos and line 
Table 4 Early and Middle Jurassic dinosaur tracks from China not described by Zhen et al. (1986) or Yang and Yang (1987)

\begin{tabular}{|c|c|c|}
\hline Ichnotaxon & Revised Ichnotaxonomy & Comments \\
\hline Sinoichnites youngi Kuhn (1958) & nomen dubium & undiagnostic; holotype lost \\
\hline Changpeipus carbonicus Young (1960) & no change & $\begin{array}{l}\text { has variously been compared to Grallator, Eubrontes and } \\
\text { Kayentapus }\end{array}$ \\
\hline Shensipus tuchuanghensis Young (1966) & no change & - \\
\hline Changpeipus luangpineris Young (1979) & nomen dubium & referred to C. carbonicus by Xing et al. (2009a) \\
\hline Lufengopus dongi Lil et al. (2006) & cf. Eubrontes & - \\
\hline Changpeipus xuiana Li et al. (2007) & Eubrontes carbonicus comb. nov. & referred to $C$. carbonicus by Xing et al. (2009a) \\
\hline Weìnanpus zigongensis Gao (2007) & Eubronteszigongensis comb. nov. & - \\
\hline Kayentapus hailiutuensis Li et al. (2010) & no change & - \\
\hline Changpeipus pareschequier Xing et al. (2009a) & Eubrontespareschequier comb. nov. & - \\
\hline $\begin{array}{l}\text { Shenmuichnus youngteilhardorum } \mathrm{Li} \text { et al. } \\
\text { (2012) }\end{array}$ & no change & $\begin{array}{l}\text { the only valid, large ornithischian ichnotaxon from the Early } \\
\text { Mesozoic of China }\end{array}$ \\
\hline
\end{tabular}

drawings of their various type specimens, but as shown by Lockley et al. (2003) and Lockley and Matsukawa (2009), the morphological details in many of the line drawings are incorrect and do not reflect the morphologies of the actual tracks. For example, Chuanchengpus wuhuangensis is depicted as having a long, sausage-shaped, clawless digit III and very short digits II and IV (Yang and Yang, 1987, fig. 21). However, based on our examination of the actual specimen, only the anterior half of the actual track was traced (Yang and Yang, 1987, pl. III-1); the complete specimen is a typical Grallator track, with a long heel, claw traces, and discrete pad traces. The comparison between the two interpretations is stark (Fig. 2) and $C$. wuhuangensis would have to be considered a nomen dubium were it not possible to reinterpret the morphology (Lockley et al., 2003, fig. 6F) and assign the ichnite to ichnogenus Grallator. While different researchers may interpret tracks differently, as in the case just described, the absence of a systematic comparison of new ichnotaxa with existing ichnotaxa is also problematic. Given the greatly improved understanding of Early Jurassic theropod ichnotaxa that has evolved since 1987, the fact that not one ichnotaxon in the Sichuan assemblage has been compared with or attributed to the contemporaneous, globally ubiquitous ichnogenera Grallator, Eubrontes, and Kayentapus is surprising, and in our opinion a telling omission. We propose several synonymies (Table 3 ) based on two bodies of evidence: (1) the comparisons already made with the aid of revised illustrations (Lockley et al., 2003; Lockley and Matsukawa, 2009; Fig. 2 herein) between these well-known ichnogenera and the ichnotaxa erected by Yang and Yang (1987) and (2) the simple fact that all of the Sichuan ichnogenera (except Chonglongpus, which is tetradactyl, and Tuojiangpus, an obvious nomen dubium due to poor preservation and expression of features) have typical theropod digital pad formulae and lack any other diagnostic features that separate them from the more ubiquitous theropod ichnotaxa. Chonglongpus hei bears a hallux impression and, therefore, is morphologically distinct from the other ichnotaxa described by Yang and Yang (1987). We agree with Yang and Yang (1987) that this warrants comparison to Gigandipus, and have previously suggested that Chonglongpus hei should be referred to Gigandipus as $G$. hei comb. nov. (Lockley et al., 2003).

Ten other Early-Middle Jurassic dinosaurian ichnotaxa from China remain for consideration (Table 4). Sinoichnites youngi was the first dinosaur track reported from China (Teilhard de Chardin and Young, 1929), although it was not named until later (Kuhn, 1958). Unfortunately, despite its historical importance, the type specimen is lost. Based on photos and descriptions in the original publication, we can only confirm that the track is a tridactyl cast about $33 \mathrm{~cm}$ wide and $30 \mathrm{~cm}$ long with blunt digit impressions. Lacking diagnostic characters, it is a nomen dubium. The type locality is not known precisely, described only as located somewhere near Shenmu City, Shaanxi Province. Although Teilhard de Chardin and Young (1929) suggested its track maker would have been similar to Iguanodon, recent work indicates that track-rich units in this area are of Early Jurassic age ( $\mathrm{Li}$ et al., 2012), substantially predating Iguanodon or, indeed, any large ornithopod. Quadrupedal, non-ornithopod ornithischian trackways that resemble Sinoichnites include Deltapodus; well-preserved trackways from this region have been assigned to the new, Moyenosauripus-like ichnotaxon Shenmuichnus youngteilhardorum ( $\mathrm{Li}$ et al., 2012).

Changpeipus carbonicus (Young, 1960) is a reasonably well-preserved theropod track that exhibits numerous features, such as its digital pad formula, that ally it to the Grallator-Eubrontes plexus (sensu Olsen, 1980); indeed, Gierliński (1994) considered it a synonym of Grallator sensu lato, a position echoed by Lockley et al. (2003) and indirectly endorsed by Xing et al. (2009a). In particular, Changpeipus carbonicus is similar to type Eubrontes (sensu Olsen et al., 1998). However, Xing et al. (2009a) considered it closer to Kayentapus (Welles, 1971). If Changpeipus and Kayentapus are indeed indistinguishable at the ichnogenus level, then Changpeipus (Young, 1960) has priority. Therefore, we agree with Xing et al. (2009a) 
that the absence of a systematic revision of all the relevant ichnotaxa makes it premature to suggest a formal synonymy. However, we may conclude that regarding the type of Changpeipus as a junior synonym of Grallator or Eubrontes, or as a senior synonym of Kayentapus, is not a satisfactory conclusion. Thus, further work is warranted.

Changpeipus carbonicus was originally interpreted by Young (1960) as having been made by a quadrupedal theropod with a small tridactyl manus. However, Zhen et al. (1989) declared that the supposed manus print required further study; subsequent workers assumed that the purported manus has no real relationship to the pes either by ignoring the report (Lockley et al., 2003; Lockley and Matsukawa, 2009) or by explicitly attributing it to a different track-making animal (Thulborn, 1990; Xing et al., 2009a).

Xing et al. (2009a) considered Changpeipus luangpingeris (Young, 1979) and Changpeipus xuiana (Lu et al., 2007) synonyms of $C$. carbonicus. While this reduced the number of accepted Changpeipus ichnospecies, Xing et al. (2009a) again increased the number by naming the new ichnospecies $\mathrm{C}$. pareschequier based on tracks in which the trace of digit IV bears only two digital pads, giving a pad formula of 2-3-2 rather than 2-3-4. We consider this a misinterpretation of the holotype because, as illustrated, it has most of the characteristics of a typical Eubrontes track, better transferred to Eubrontes pareschequier comb. nov. (Table 4). Normally, the posterior heel pad traces are continuous with those of the more anterior traces of digit IV; in the case of $C$. pareschequier, this is clearly seen (Xing et al., 2009a, pl. 1), indicating that their drawing (Xing et al., 2009a, fig. 4) does not adequately represent the morphology of the holotype, giving it the exaggerated impression of a large heel pad that is not connected to digit IV.

As is the case with so many Chinese Jurassic theropod tracks, as admitted by Xing et al. (2009a), synonymy is likely: some have proposed synonymy of Changpeipus with Grallator (Gierliński, 1994). However, for clarification, we note that the synonymy in this case is with Grallator sensu lato, which includes Eubrontes (Gierliński, 1994). Bearing in mind that Changpeipus cannot be synonymized with the later-named Kayentapus (Welles, 1971), both because of publication order and because it differs morphologically, it could beconsidered a synonym of Eubrontes. As argued by Gierliński (1994) and reiterated by Lockley et al. (2003), Lockley and Matsukawa (2009), and Xing et al. (2009a), the larger, Early-Middle Jurassic theropod tracks from China cannot be distinguished from Eubrontes, or in some cases Kayentapus, without resorting to finely delimited, qualitative distinctions, mostly minor digit divarication angles that may well be attributable to foot-substrate interactions and/or differences in track maker behavior. Attempts to quantify the differences, based on the most rudimentary measurements (footprint length and width) result only in scatter diagrams in which data for each ichnotaxon overlaps with the next, revealing no meaningful morphological distinctions, statistical or otherwise (Lu et al., 2007; Xing et al., 2009a).

Another example of this same kind of problem is Lufengopus dongi (Lü et al., 2006), a relatively poorly preserved, isolated track that yielded only one measurement that appears to plot along the same regression line as various other theropod tracks, including Grallator and Eubrontes. Lü et al. (2007) subsequently plotted Changpeipus xuiana on the same graph; it, too, fell within the same field as Eubrontes. Neither of these ichnospecies therefore has diagnostic characters that can distinguish them from well-established ichnotaxa, such as Eubrontes and Grallator.

In summary, with the exception of the probable crocodylian track Kuangyuanpus (Young, 1943), the nomen dubium Sinoichnites, the ornithischian track Shenmuichnus, and Shensipus (a distinctive and possibly valid ichnotaxon of uncertain affinity), all of the other Early and Middle Jurassic ichnotaxa from China can be assigned to one of only five ichnogenera: Changpeipus, Grallator, Eubrontes, Kayentapus, or Gigandipus. This simplification brings the Chinese ichnofauna into line with those reported from other parts of the world (reviewed by Lucas, 2007).

\subsection{Late Jurassic Ichnospecies}

Three dinosaurian ichnospecies have been reported from the Upper Jurassic of China. These are, in the historical order of naming, Yangtzepus yipingensis (Young, 1960; Zhen et al., 1986), Jialingpus yuechiensis (Zhen et al., 1983), and Huanglongpus shengouensis (Yang and Yang, 1987) (Fig. 3). Yangtzepus yipingensis (Young, 1960) is based on an elongate, tridactyl type specimen that has minimal divarication angles between the digit traces, and has a purported digital pad formula of 23-3. Based on the illustrations Young (1960) provided, a formula of 2-3-4 could as easily be inferred, indicating a theropod track maker. Young (1960) also claimed to see "coarsely granulated" skin impressions, although we have been unable to confirm this observation. He also claimed that one of the two other, smaller specimens, although seriously damaged, was certainly a manus trace. This, in turn, suggested to Zhen et al. (1989) that the track might be of ornithopod affinity. However, little, if any, evidence supports this interpretation, and we infer that the type pertains to a bipedal theropod, and that the paratypes have 


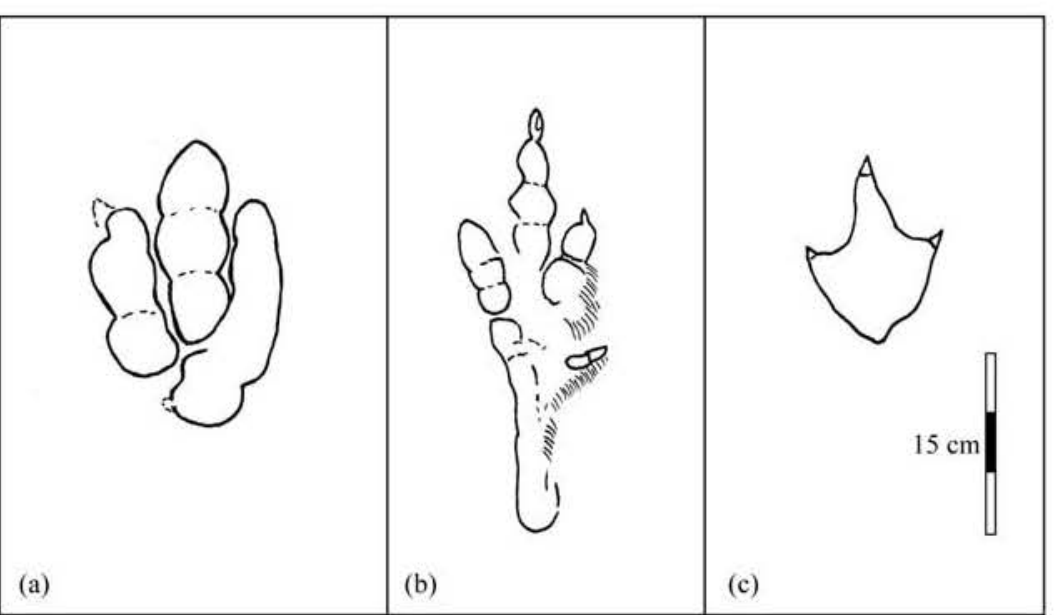

Fig. 3. Late Jurassic theropod tracks of China.

(a), Yangtzepus yppingensis (Young, 1960); (b), Jialthgpus yuechitensts (Zhen ot al., 1983); (c), Huanglongpuss shengovensis (Yang of Yang 1987)

uncertain relationships to the holotype. Yangtzepus has a "fleshy" or well-padded appearance somewhat reminiscent of Therangospodus, an Upper Jurassic ichnogenus known from Europe and North America (Lockley et al., 2000) that has recently also been reported from China (Xing et al., 2011a). Because it is based on well-preserved material, and morphological characteristics, (thick, "fleshy" digit traces and low digit divarication angles), Yangtzepus is retained here as a valid ichnotaxon.

Jialingpus is the most distinctive Late Jurassic track reported from China. It is based on a sample of wellpreserved natural casts that have well-defined digital pad impressions, reminiscent of Grallator; this is true even for an unusual specimen that has a well-defined hallux and metatarsal trace. Because of the hallux and metatarsal trace, Zhen et al. (1989) compared Jialingpus to Anomoepus and placed it in the ichnofamily Anomoepopodidae (Lull, 1953), but without explicitly stating that the tracks were of omithischian affinity (Lockley and Gillette, 1989). At that time, few theropod tracks with metatarsal and hallux traces had been reported, whereas now they are much better known (Lockley et al., 2003; Gierlinski et al., 2009). The anomoepodid attribution is almost certainly incorrect, as already stated by Lockley et al. (2003), and we infer the ichnogenus pertains to a theropod track maker. Its distinctive morphology of well-preserved pads and hallux and metatarsal traces indicates that Jialingpus, is Grallatorlike. Like so many theropod tracks discussed here, it is in need of detailed comparison with other ichnotaxa, and pending such an analysis, we retain it as valid here. We emphasize that Grallator cannot be ruled out as the appropriate ichnotaxon for these specimens solely based on their Late Jurassic age: Grallator tracks have also been reported from Lower Cretaceous strata, especially in China (see below). But more importantly, ichnotaxa are diagnosed by morphological features, not ages or presumed track maker affinities.

Huanglongpus shengouensis (Yang and Yang, 1987) is based on a poorly preserved, elongate, tridactyl track that is $16 \mathrm{~cm}$ long. It has sharp claw traces (Yang and Yang, 1987, fig. 19), but lacks diagnostic pad traces. The poor quality of preservation renders Huanglongpus a nomen dubium.

\subsection{Revised Tetrapod Ichnotaxonomy for} the Jurassic of China

Aside from the crocodylian
Kuangyuanpus, the ornithischian

Shenmuichnus and Sinoichnites, and the unassigned Shensipus, all other Jurassic ichnotaxa from China that are not nomina dubia pertain to theropods. Only three of these ichnospecies were originally placed in non-endemic ichnogenera (Grallator limnosus, Eubrontes platypus, and Kayentapus hailiutuensis). We conclude that only five theropod ichnogenera are valid and useful for describing Chinese theropod tracks from the Early and Middle Jurassic: Eubrontes and Grallator (both of which are relatively ubiquitous), Kayentapus and Gigandipus (which are less common but still known across much of the Northern Hemisphere), and Changpeipus, which may be a senior subjective synonym of Kayentapus. If further study supports this latter synonymy, the ichnogeneric diversity would shrink further from five to four. Two Late Jurassic theropod ichnogenera that we provisionally retain are the Therangospodus-like Yangtzepus and the Grallator-like Jialingpus. The only well-defined, nontheropod tracks from the Early and Middle Jurassic of China are Shenmuichnus and Kuangyuanpus, respectively of omithischian and crocodylian affinities. Four other ichnogenera and ichnospecies constitute nomina dubia. Thus, the previous diversity of 28 endemic Chinese Jurassic tetrapod ichnospecies in 23 ichnogenera (excluding non-endemic Eubrontes platypus) reduces to only 10 ichnogenera of which seven represent theropods. Sixteen of the 24 unequivocal theropod ichnospecies $(\sim 67 \%)$ are accommodated in just three ichnogenera (seven in Eubrontes, excluding E. platypus, four in Grallator, and five in Kayentapus). All of the ichnogenera compare favorably to other Jurassic ichnogenera from other continents, enhancing their utility for various paleobiological and paleobiogeographical comparison and analyses. 


\subsection{Cretaceous Ichnospecies: General Comments}

Thirty-four tetrapod ichnospecies assigned to 30 ichnogenera have been named from the Cretaceous of Ching. Of these, 32 pertain to dinosaurs, seven of which are birds, and one each to a pterosaur and a crocodylian. The majority of these 34 are Early Cretaceous in age, but the exact ages of some are uncertain. For this reason, the following descriptions are generally presented in the historical order in which they were described, and readers interested in age estimates should consult the original sources we cite.

\subsection{Early Cretaceous Ichnospecies}

The first named Cretaceous ichnospecies in China was Jeholosouripus s-satoi (Yabe et al., 1940) which at the time was thought to be pre-Cretaceous in age (Fig. 4). The ichnospecies, later renamed Grallator ssatoi (the ichnospecies name emended to reflect the International Code of Zoological Nomenclature dictum against punctuation marks in names) by Zhen et al. (1989), originated from the Tuchengzi Formation, a unit considered Late Jurassic through basal Cretaceous in age, in Liaoning Province. More than 1000 tracks have been documented at the site from which the holotype of $G$. ssatoi came (Matsukawa et al., 2006). Whether or not $G$. ssatoi is readily distinguishable from other Grallator ichnospecies remains unclear. However, the synonymy of this ichnotaxon with Grallator seems reasonable and uncontroversial on morphological grounds.

Despite the large number of theropod tracksites described from Liaoning Province, fow have yielded track assemblages different from those described by Yabe et al. (1940). Although a few theropod tracks from these sites have recently been attributed to previously described

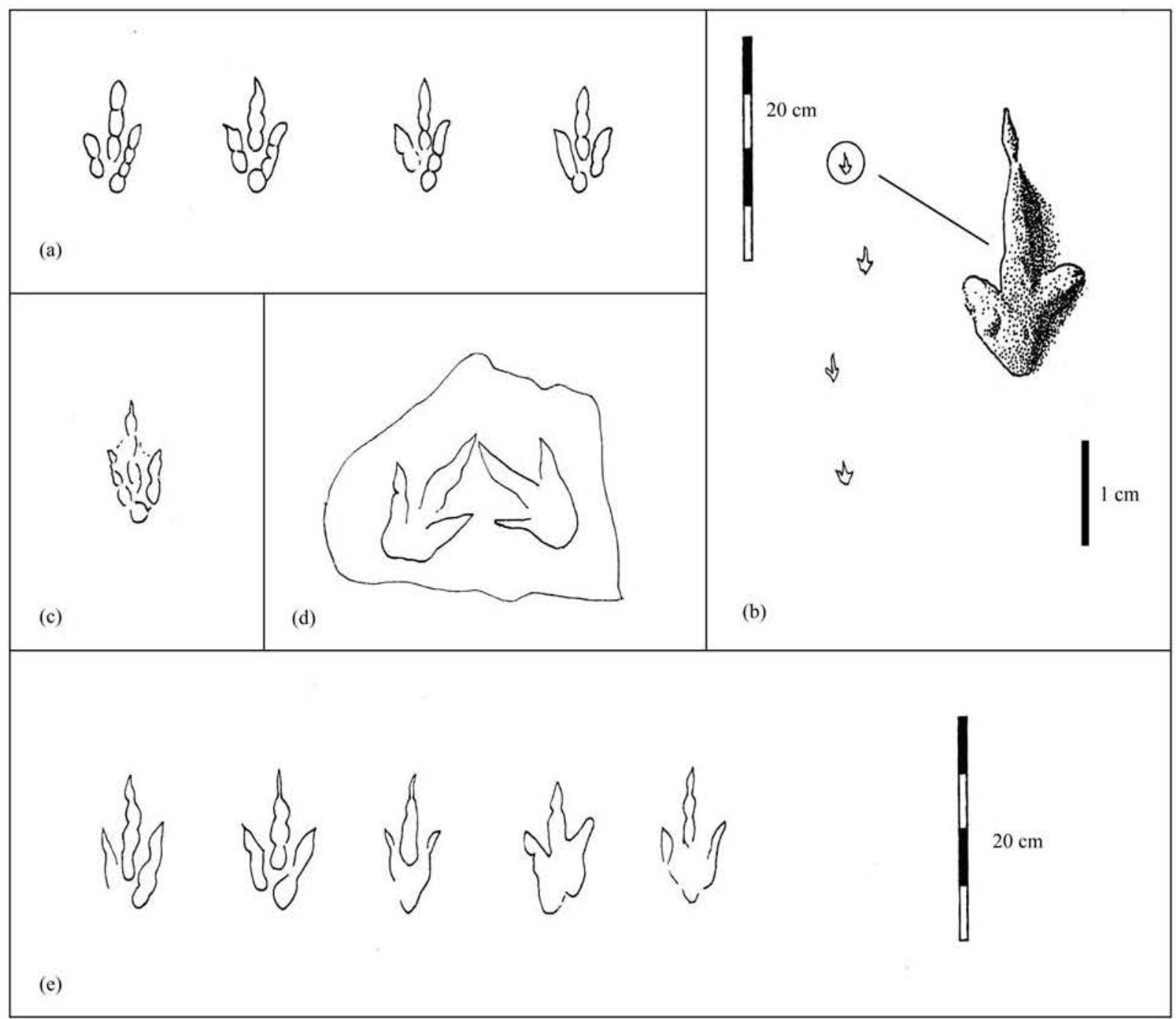

Fig. 4. Grallatorid tracks from the Cretaceous of China.

(a), Grallator ssatoi topotypes from Lizoning, (b), Grallator emeiensis from Sichuan (after Zhen et al, 1994; Matsulawa et al., 2005); (c), Paragrallator masiengensis from the Late Trisssic of Lesotho, southern Africa (after Ellenberger, 1972); (d), type specimen of Paragrallatar yangi (after Lockley et al, 2012), herein refenred to Grallator yengi comb. nov.; (e); Grallatorid tracks referred to Paragrallator by Lockley et a1. (2012), referred herein to Grallator yangi comb. nov. All tracls drawn to same scale except for detail of $G$. emeiensis. 
ichnotaxa, such as Therangospodus and Megalosauripus (Xing et al., 2011a), only one additional ichnotaxon has been named: Menglongipus sinensis (Xing et al., 2009b). $M$. sinensis is based on a poorly preserved trackway of a purportedly didactyl (deinonychosaurian) theropod. Although individual tracks are difficult to distinguish from poorly preserved tridactyl tracks, as admitted by Xing et al. (2009b), the occurrence of a trackway sequence of didactyl traces is sufficient evidence for us to retain this name, at least provisionally.

After Grallator ssatoi, the next tetrapod ichnotaxon named was Laiyangpus liui (Young, 1960), which was initially interpreted as a theropod track but later reinterpreted as of crocodylian affinity (Lockley et al., 2010). Unfortunately, the type specimen of $L$. liui is lost, so the degree to which it is diagnostic can only be gauged with uncertainty through published photographs and descriptions.

Zeng (1982a, b) reported three new ichnospecies from a single slab from the Cretaceous Xiaodong Formation of Hunan Province (Fig. 5). The first of these, Hunanpus jiuquwanensis, is based on a moderately well-preserved, small theropod track similar to others found in situ at the type locality (Matsukawa et al., 2006, fig. 5). The other two tracks, Xiangxipus chenxiensis and $X$. youngi were assigned to the same ichnogenus, despite being rather different in appearance. $X$. chenxiensis is a slender-toed, tridactyl track with a wide total digit divarication that resembles a number of ichnotaxa assigned to the Ornithomimipodidae (Lockley et al., 2011b). The two consecutive $X$. chenxiensis tracks differ in mode of preservation, suggesting that while the first in the sequence is clearly tridactyl, the second in sequence, which is technically the type, appears tetradactyl, evidently due to one of the digits having left a double trace (Fig. 5). The differences between the larger $X$. chenxiensis and the smaller $X$. youngi, which also has wide digit divarication angles and wider or more robust digit traces, may be sufficient to place the latter form in a different ichnogenus. As noted below, $X$. youngi is similar in size and digit divarication to Wupus agilis (Xing et al., 2007), but even if this synonymy is demonstrable, the question of whether both Xiangxipus chenxiensis and $X$. youngi belong in the same ichnogenus is not resolved. However, none of the Hunan tracks are obvious synonyms of ichnotaxa named before 1982, and so the names provisionally stand, although they should be researched further.

Chen and Huang (1993) erected Chuxiongpus changlinensis and $C$. zheni for two morphologically similar, indifferently-preserved sauropod tracks from the Cretaceous of Yunnan (Fig. 5). Lockley et al. (2002) considered $C$. zheni a synonym of $C$. changlinensis and further synonymized the ichnogenus with Brontopodus, producing $B$. changlinensis comb. nov. The track of a tridactyl biped named Yunnanpus huangcaoensis (Chen and Huang, 1993) is poorly preserved and must be considered a nomen dubium.

Zhen et al. (1994) reported an important Cretaceous ichnofauna from the Emei region of Sichuan Province that included four new tetrapod ichnospecies: Velociraptorichnus sichuanenesis, Minisauripus chuanzhuensis, Grallator emeiensis, and Aquatilavipes sinensis, in addition to so-called Iguanodon track; the latter was later formally named Iguanodonopus xingfuensis (Zhen et al., 1996). V. sichuanenesis and $M$. chuanzhuensis are highly distinctive and unlike anything previously reported. The former ichnospecies is universally accepted as the first track to have been correctly attributed to a functionally didactyl, deinonychosaurian theropod. Minisauripus was initially attributed to a small ornithopod, but it has since been interpreted as the track of a theropod (Lockley et al., 2008). G. emeiensis, mislabeled in the figure caption as Neograllator emeiensis (Zhen et al., 1994, fig. 3), is convincingly interpreted as a small theropod. However, $I$. xingfuensis is a poorly preserved, non-diagnostic theropod track, not an ornithopod track as the name and original interpretation proposed. It is here regarded as a nomen dubium, in agreement with Xing et al. (2009c). However, we do not agree with the latter authors that it can be transferred to Iguandontipus (Sarjeant et al., 1998) either on the basis of morphology or historical priority. In our opinion, no more precise identification than "grallatorid indet." is possible. The Emei avian track named Aquatilavipes sinensis is more similar to type Koreanaornis (Kim, 1969; Lockley et al., 1992; Lockley and Harris, 2010) than to type Aquatilavipes, and therefore has been transfered to Koreanaornis sinensis (Lockley et al., 2008, 2012).

The "grallatorid" track Paragrallator yangi ( $\mathrm{Li}$ and Zhang, 2000; $\mathrm{Li}$ et al., 2002) from Shandong Province is problematic because it was named without reference to the grallatorid track Paragrallator masiengensis erected by Ellenberger (1972), albeit without a formal description (making it a nomen dubium). Xing et al. (2010) declared $P$. yangi a nomen dubium; Lockley et al. (2011) reillustrated the type material and considered it in need of revision. Although the type specimen is not very well preserved, a large sample of very well-preserved tracks ascribed to Paragrallator was described from another Shandong locality (Zhucheng area) by $\mathrm{Li}$ et al. (2011). These authors also identified the new and highly distinctive theropod ichnospecies Corpulentapus lilasia 
from the Zhucheng sample. In light of the "priority" of the Paragrallator as poorly applied by Ellenberger (1972), the name cannot be used as the ichnogenus to accommodate the yangi ichnospecies, which must either be moved to a suitable existing ichnogenus (e.g., Grallator yongi) or put in a new ichnogenus. Pending the results of an in-progress, further study of the abundant material from Shandong, we here make no recommendations regarding these options.
The Early Cretaceous bird track Pullomipes aureus (Lockley et al., 2006) from Liaoning Province (Fig. 6) is distinctive: its well-developed hallux, separate (nonconnected) digit traces, long step, and slight inward rotation are unlike any avian ichnotaxon previously described, and therefore the ichnotaxon is treated here as valid. Despite the abundance of avian body fossils from Liaoning, this was the first avian ichnospecies named from this region. The

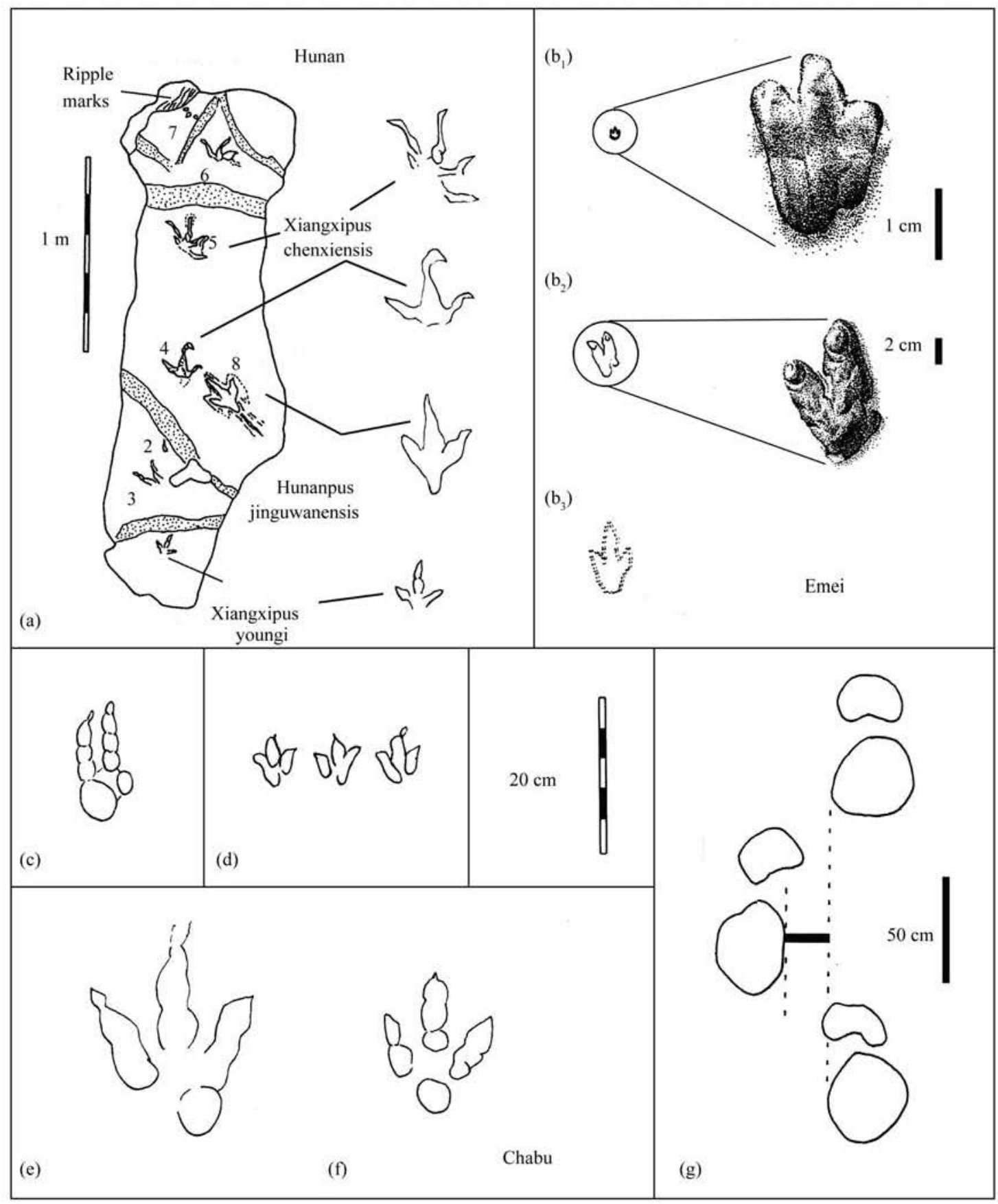

Fig. 5. Early Cretaceous tetrapod ichnofauna of China.

(a), the Human ichnofauna, comprising (1) Xiangxipus chenxiensis (Zong, 1982a, b), (2) Xiangxijpus youmgi (Zeng, 1982a, b), and (3)

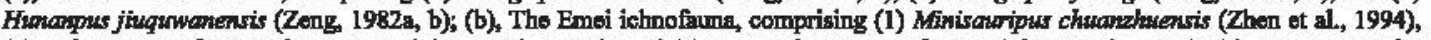
(2) Velociraptortchsus sichuamenesis (Zhen et al., 1994), and (3) Iguomodonpus xingfivensis (Zhen ot al., 1996); (c), Dromaeopodus shandongensis (Li et al, 2008); (d), Corpulentapus Illasia (Li et al, 2011); (e), Chapus lockieyi (Li ot al,, 2006); (f), Asianopodus robustus (Li ot al., 2011) from the Chabu ichnofauma; (g), Brontopadus changlisensis (Lockloy et al., 2002). 


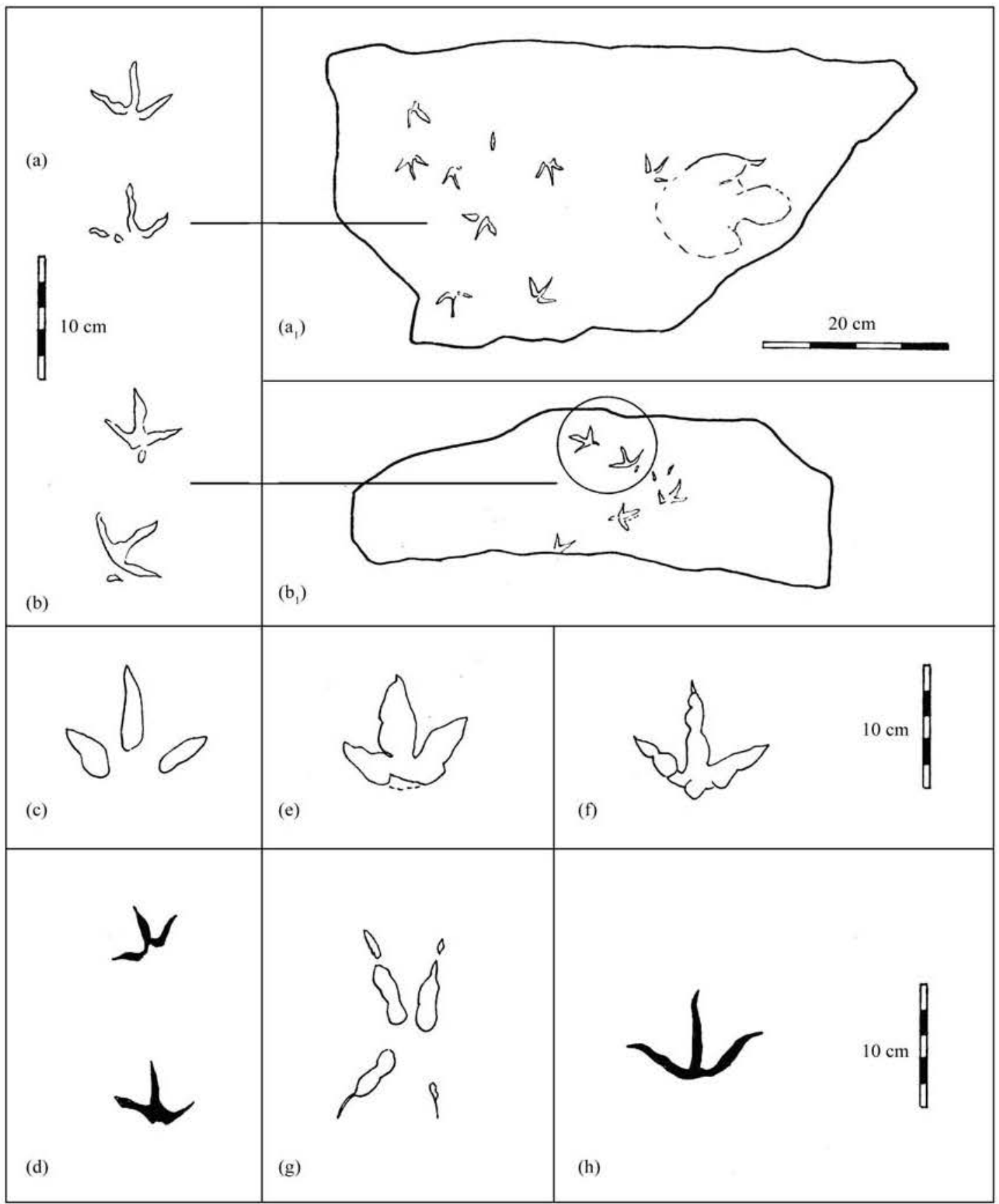

Fig. 6. Bird tracks from the Cretaceous of China.

(a), Koreanaomis sinensis, comb. nov. (modified after Matsolsawa et al, 2006); (b), Koreanaornis anksiensis comb. nov.; (c), Koreancormis dodsoni (after Xing et al, 2011); (d), Kareanoornis hamasnensis topotypes from the Earty Cretaceous of Korea for compariBon with a-c; (e), Moguiornipes robusta (after Xing et al, 2011); (f), Shandongornipes muxial after Li et al, 2005); (g), Aquatilavipes swiboldae (Currie, 1981) from the Earty Cretaceous of Canada for comparison with a-f.

new ichnospecies Pteraichnus yanguoxiaensis (Peng et al., 2004) described from the Early Cretaceous of Hekou Group of Gansu Province, was the first pterosaurian ichnotaxon described from China, but is difficult to distinguish from other ichnospecies of Ptercichnus (Lockley and Harris, in press). Recently, another ichnospecies from Gansu, the third deinonychosaurian ichnotaxon known from China, was named Dromaeasauripus yongingensis (Xing et al., in press). Another highly distinctive bird track, Shandongornipes muxiai (Li et al., 2005; Lockley et al., 2007) was reported from a site in the Juman area of Shandong Province that also yielded the large, highlydistinctive, and well-preserved, dromaeosaurid track Dromaeopodus shandongensis ( $\mathrm{Li}$ et al., 2008), a new ichnospecies of Minisauripus, M. zhenshounani (Lockley et al., 2008), and large ornithopod tracks (cf. 
Ornithopodichmus).

New ichnospecies have also been reported from the Early Cretaceous of Nei Mongol, including the large theropod track Chapus lockleyi (Li et al., 2006), the theropod track Asianopodus robustus ( $\mathrm{Li}$ et al, 2011), and the bird track Tatarornipes chabuensis (Lockley et al., 2012), all of which are herein retained as valid.

Most recently, Xing of al. (2011b) reported a birddominated ichnofauna in the Tugulu Group of Xinjiang Province associated with tracks assigned to existing theropod ichnogenera (Asianopodus, Kayentapus, and cf. Jialingpus). In addition, these authors erected two new avian ichnospecies: Koreanaornis dodsoni and Moguiormipes robusta. $K$. dodsoni is somewhat larger than other ichnospecies assigned to Koreanaomis (Fig. 6). Size is generally a weak character on which to base an ichnotaxonomic diagnosis, and it may be that the ichnospecies belongs in a different combination, e.g., Aquatilavipes dodsoni. However, until further work is completed, the $\boldsymbol{K}$. dodsoni is provisionally regarded as a distinct ichnotaxon. $M$. robusta, as the name suggests, has unusually wide digit traces, which arouses suspicion that extramorphological factors may have played a role in the preservation of the tracks. Such variation was examined in detail in the description of Tatarornipes from Nei Mongol (Lockley et al, 2012). Pending further investigations, we consider $M$. robusta provisionally valid.

\section{7 "Middle" and Late Cretaceous Ichnospecies}

Based on current age assessments, the 27 Chinese type ichnospecies discussed in the previous section are all Early Cretaceous in age. The remaining six Cretaceous ichnotaxa are "middle" or Late Cretaceous.

Xing et al. (2007) named four new ichnospecies from the "middle" Cretaceous Jiaguan Formation of Chongqing. These tracks were illustrated with only line drawings, not photographs, and are therefore difficult to assess (Fig. 7). These named ichnotaxa comprise Wupus agilis, attributed to a theropod, and Laoyingshanpus torridus, Caririchnium lotus, and Qijiongpus sinensis, all attributed to omithischians. W. agilis is a small but abundant tridactyl track with a long step and wide digit divarication (Wang 2012) that as noted above, could be tentatively compared with $X$, youngi from Hunan Province. $L$. torridus, a functionally tridactyl track with a poorly defined trace of a hallux, appears to be another nomen dubium. C. lotus, the best-preserved and most abundant track type at the site, pertains to a facultatively quadrupedal ornithopod. The tridactyl pes prints possess the quadripartite pes print morphology typical of the ichnogenus, and smaller manus prints, similar to those of type Caririchnium leonardii from Colorado (Lockley, 1987; Lockley et al., 2001). Lastly, $Q$. sinensis was described as the track of an ankylosaur with a tetradactyl manus and a pentadactyl pes. The tracks are poorly preserved and a clear trackway configuration was not reported. The ichnotaxon appears to have no diagnostic features and, based on a reexamination of the type by two of us (MGL and XL) in 2012, we regard it as a nomen dubium, as noted below. 
A new avian ichnospecies, Aquatilavipes anhuiensis, was briefly described (with minimal information) from the Late Cretaceous of Anhui Province (Jin and Yan, 1994). As with the aforementioned Sichuan ichnospecies of Aquatilavipes, it is unlike type Aquatilavipes, in revealing a small hallux trace (Fig. 6), and we herein transfer it to Koreanaornis anhuiensis comb. nov.

Large ornithopod tracks from the Late Cretaceous of Heilongjiang China formed the basis for Jiayinosauropus johnsoni (Dong et al., 2003); similar tracks from southern China were named Hadrosauropodus nanxiongensis (Xing et al., 2009c) because of their similarity to Hadrosauropodus langstoni (Lockley et al., 2004). $H$. nanxiongensis tracks are not well-preserved, although they occur in a trackway. Jiayinosauropus is similar to Hadrosauropodus; if congeneric, then Jiayinosauropus has nomenclatural seniority. However, as pointed out by Xing et al. (2009c) the posterior margin of Jiayinosauropus tracks are not clearly defined, rendering diagnostic characteristics difficult to ascertain. In contrast, the type of $H$. langstoni is well preserved, even displaying skin impressions. We provisionally retain Jiayinosauropus here as valid pending further investigation.

\subsection{Revised Tetrapod Ichnotaxonomy for the Cretaceous of China}

In contrast to type Chinese Jurassic ichnotaxa, type Cretaceous ichnotaxa have been named rather more judiciously. We contend that six highly distinctive, wellpreserved forms-Velociraptorichnus, Minisauripus, Shandongornipes, Pullornipes, Dromaeopodus, and Corpulentapus - are impossible to assign to any previously established ichnotaxon. In addition, 13 Chinese Cretaceous ichnospecies have been erected in previously established ichnogenera: Aquatilavipes (two ispp.), Asianopodus, Brontopodus (two ispp. referred), Caririchnium, Grallator (two ispp.), Hadrosauropodus, Koreanaornis, Minisauripus, Dromaeosauripus and Pteraichnus. Some of these might be subjective junior synonyms of existing ichnospecies, but they otherwise appear secure in the ichnogenera to which they are currently assigned.

Fifteen other ichnotaxa (Table 1) are more problematic. Of these, Paragrallator needs to be assigned to either a new or an existing ichnogenus (possibly Grallator) because the ichnogenoholotype is a nomen dubium. We also consider Qijiangpus sinensis a nomen dubium. Two of the present authors (MGL and LX) reexamined the type tracks (purported manus and pes) and regard them as poorly preserved, compound tracks made by ornithopods.

The Chinese ichnospecies Iguanodonopus is a nomen dubium, as are the ichnogenera Yunnanpus and
Laoyingshanpus, all due to poor preservation that make identifying diagnostic characters impossible. Leaving aside the type of Laiyangpus, which is lost (Lockley et al., 2010), seven ichnogenera and ichnospecies-Xiangxipus (two ispp.), Hunanpus, Jiayinosauropus, Chapus, Tatarornipes, and Moguiornipes-are provisionally regarded as valid. However, we suspect that several of these ichnotaxa will require detailed ichnotaxonomic analysis, comparative study, and/or revision in the near future.

As is the case with Jurassic theropod ichnotaxa, differentiating many Cretaceous theropod track ichnotaxa is equally challenging. For example, although globally ubiquitous Early Jurassic forms, such as Grallator and Eubrontes, are less commonly reported from the Cretaceous, legitimate Cretaceous examples of Grallator have been most confidently identified from China, where it is remarkably abundant (Matsukawa et al., 2006). If the mislabeled Paragrallator and the grallatorid morphotype Hunanpus genuinely are synonyms of Grallator, the abundance of Grallator in the Cretaceous of China is particularly striking and reduces the apparent global ichnodiversity among Cretaceous theropod tracks. This raises the question as to whether other Jurassic theropod ichnotaxa, such as Eubrontes, Kayentapus, or Changpeipus, are represented in the Cretaceous. It would be constructive, for example, to compare Chapus with such Jurassic ichnotaxa. As noted below, the differentiation of non-avian theropod and non-theropod ichnotaxa is less problematic.

\section{Discussion and Synthesis}

Chinese Mesozoic tetrapod track types have been placed into 63 ichnospecies (one Triassic, 28 Jurassic, and 34 Cretaceous), exclusive of other non-type ichnospecies or ichnotaxa identified from China. Fifty-two ( $83 \%)$ of these 63 tetrapod ichnospecies were placed in monospecific ichnogenera. Of the 29 Triassic and Jurassic ichnospecies, one track pertains to a crocodylian and two pertain to ornithischian dinosaurs; all the rest ( $\sim 89 \%)$ pertain to non-avian theropods. As has been noted previously, most of these ichnospecies are subjective junior synonyms of various Grallator ispp. and Eubrontes ispp.; many are best considered synonymous at the ichnogeneric level. Two of the 34 Cretaceous ichnospecies pertain to non-dinosaurs (a crocodylian and a pterosaur); the remaining 32 pertain to dinosaurs, of which 18 ( $56 \%)$ pertain to non-avian theropods and seven $(\sim 22 \%)$ to avian theropods (birds). The remaining seven ( $22 \%)$ pertain to sauropods and ornithischians.

Of the 63 Chinese Mesozoic tetrapod ichnospecies, 53 
$(\sim 84 \%)$ pertain to dinosaurs, and all but 10 to non-avian theropods. Nine of these 10 are Cretaceous in age, and seven of them pertain to birds. Fewer Chinese Cretaceous ichnospecies are obvious nomina dubia or subjective synonyms, in sharp contrast to the situation in the Jurassic. Nevertheless, Chinese dinosaur ichnotaxa are oversplit, so making objective decisions about which ichnotaxa are obvious subjective synonyms or nomina dubia is difficult without familiarity with the type specimens and both the relevant Chinese and non-Chinese literature. However, the authors of this paper have collectively seen all the type material (except for two holotypes that are lost), in order to arrive at the ichnotaxonomic revisions presented above. At the ichnogenus level, we prune (either by recognizing nomina dubia or by synonymy) 17 from the list of 53 dinosaurian ichnogenera (a 32\% reduction), leaving 36 valid ichnotaxa. Most of the cuts affect Jurassic ichnotaxa, which are reduced from 23 to only nine. Ichnospecies differences arguably are subtle, so we provisionally retain ichnospecies as valid pending detailed analyses of differences between congeneric ichnospecies. Such a synthesis is long overdue and is necessary to address the problems of historical and provincial ichnotaxonomy, which severely hamper comparisons of tetrapod ichnofaunas in space and time. Identification of such provincial ichnotaxonomic practices strongly cautions against the casual introduction of new names, especially when the workers erecting such ichnotaxa fail to make sufficient comparisons to other published ichnotaxa and/or properly account for foot-substrate interactions and other extramorphological phenomena. We would also advise against using very slight or subtle differences (e.g., small differences in digit divarication angles), that other workers would not also recognize, as the basis for ichnotaxonomic distinctions, especially in the case of small samples.

Of the 63 type tetrapod ichnospecies hitherto identified from the Mesozoic of China, 10 are nomina dubia. Of the valid ichnospecies, 37 pertain to non-avian theropods and another seven to avian theropods (birds). This high proportion appears to indicate a genuine abundance of non-avian theropod footprints in the Chinese track record. However, the sheer abundance of such tracks does not necessarily equate to a comparably high ichnodiversity. Despite the relatively conservative nature of the theropod foot, which would logically translate to low ichnotaxonomic diversity, Chinese theropod ichnotaxonomy has historically, but counterintuitively, suggested an apparently high ichnodiversity. As demonstrated particularly in the Jurassic, this apparent high diversity is an artifact of provincial ichnotaxonomy and, as a result, "splitting" single morphologies into numerous ichnotaxa in need of comprehensive revision.
Recent studies (e.g., Gierliński, 1994; Lockley et al., 2003; Lockley and Matsukawa, 2009; Xing et al., 2009a) have taken small steps in this direction. With this in mind, and with the modern ease of access to global ichnologic literature, we therefore appeal to ichnotaxonomists (in China and elsewhere) to exercise caution and restraint when erecting new ichnotaxa. New ichnotaxa (1) should always be based on (preferably multiple) examples of well-preserved, morphologically distinct specimens, and (2) require detailed description, illustration, and thorough, comprehensive comparisons to existing ichnotaxa from all continents and from all time periods (q.v., Sarjeant, 1989). Adherence to this practice avoids ichnotaxa that are either obvious synonyms of existing ichnotaxa, poorly preserved, and/or otherwise undiagnostic. Such illconceived ichnotaxa are essentially useless because they hinder understanding of regional and global ichnological trends through time.

The need to conduct careful comparative analyses reminds us that there are a few tetrapod ichnotaxa (ichnogenera and ichnospecies) reported from China that are not endemic types cited herein (Table 1). These include representatives of the ichnogenera Chirotherium isp. from the Triassic ( $\mathrm{Lu}$ et al., 2004), Anomoepus (Lockley and Matsukawa, 2009) and Eubrontes (Zhen et al., 1986) from the Early Jurassic, Therangospodus isp. and Megalosauripus isp. from the Late Jurassic (Xing et al., 2011a), Anchisauripus from near the JurassicCretaceous boundary (Sullivan et al., 2009), and Dromaeosauripus (Xing et al., in press) from the Early Cretaceous. This increases the estimated 35 valid endemic tetrapod ichnogenera reported from the Mesozoic of China by adding about $20 \%$ to a combined total of 42 endemic and non-endemic ichnogenera.

New discoveries and further, careful study of Chinese tetrapod ichnotaxa will doubtlessly change these ichnotaxonomic lists and diversity estimates. We recognize that our study is a preliminary synthesis, and that a large part of ichnotaxonomy involves the investigation of subjective synonymies. Therefore, investigating the validity of most ichnospecies is beyond the scope of this paper; similarly, evidence of their variability, if available, is likewise not analyzed, largely because many ichnospecies are based on very small samples. However, as shown above, investigation of Chinese ichnotaxa at the ichnogenus level reveals that a substantial number are morphologically indistinguishable from well-known ichnogenera from other regions that, in most cases, have nomenclatorial priority. Assigning these ichnospecies to appropriate ichnogenera, creating new combinations, is thus relatively easy. In cases where poor preservation (or incorrect morphological interpretation) of 
ichnotypes is clearly demonstrable, ill-conceived ichnotypes can be declared nomina dubia. As noted above, such weeding out of invalid names is essential to enable progress toward more standardized and useful ichnotaxonomies. As Lucas (2007) suggested, this may involve recognizing that, in the majority of cases, ichnogenera are the most useful "units of currency" for comparative morphology and correlation because differentiating ichnospecies within given ichnogenera is highly subjective, both for specialist and non-specialist ichnologists. Moreover, current literature provides many examples of ichnogenus-level correlations (Lucas, 2007 and references therein), but few, if any, useful or convincing examples of widely used ichnospecies-level correlations, even at the local or regional level. The aim of a more standardized consensus in naming ichnotaxabeginning, as attempted here, at the ichnogenus level - can only be achieved by imploring vertebrate ichnologists to conduct careful comparative analyses and name new ichnotaxa judiciously and without unwarranted provincial bias.

\section{Conclusions}

Although this study is preliminary, it is nevertheless sufficiently broad in scope to reach some tentative, quasiquantitative conclusions regarding both apparent and real Chinese tetrapod ichnodiversity:

(1) The total number of valid Triassic through Cretaceous type ichnogenera from China can be reduced by $35 \%$ from 54 to 35 . This reduction is quite conservative because it provisionally retains some questionable ichnogenera that are in need of further study.

(2) Seven additional tetrapod ichnogenera based on non-endemic ichnites, named outside China, increases total ichnogenus diversity to 42 .

(3) The Chinese Triassic tetrapod track record is sparse, with only one type ichnospecies reported, which is treated as valid herein.

(4) The Jurassic track record reduces, by $\sim 57 \%$, from an initial, perceived ichnogeneric diversity of 23 to 10 ichnogenera of global (or, at least widespread) distribution. This marked reduction in provincial ichnogenera from the Jurassic reflects the general global uniformity of Jurassic ichnofaunas and the widespread distribution of Grallator-Eubrontes-dominated assemblages (Lucas, 2007), as is expected from greater paleogeographic uniformity in the Jurassic.

(5) The Chinese Cretaceous track record required less drastic pruning than the Jurassic record: based on our analysis, the record reduces, by $\sim 17 \%$, from 30 to 25 ichnogenera by recognizing five nomina dubia. Of the remaining 25 ichnogenera, ten are assigned to ichnogenera whose ichnogenoholotypes are specimens discovered outside China. The remaining 15 (60\% of) Cretaceous ichnogenera first described in China appear genuinely endemic to either China or East Asia, and six of these are highly distinctive.

(6) The Cretaceous percentage of endemic ichnotaxa is not such a pronounced expression of provincial ichnotaxonomy as was the case with the Jurassic. Indeed, Cretaceous tetrapod ichnofaunas reflect greater endemicity and are apparently more diverse than those from any other region.

(7) The historic practice of naming new provincial ichnotaxa, especially ichnogenera, without careful comparison to ichnofaunas from other areas, has produced far too many junior synonyms, especially in the Jurassic. The result has been serious obstruction of global correlations and comparative analyses.

(8) The present synthesis aims only to eliminate the most obvious ichnogeneric synonyms. Further analysis is necessary to assess the validity of individual ichnospecies.

\section{Acknowledgements}

Several institutions and organizations helped support this work and the studies on which it was based. Preliminary investigations of many sites in 1999-2001 were supported by the Grant-in-Aid for Scientific Research of the Japan Society for the Promotion of Science (to Masaki Matsukawa, no. 1183303, 1999 2000), and the Grant-in Aid for University and Society Collaboration of the Japanese Ministry of Education, Science, Sports and Culture (to Masaki Matsukawa, no. 11791012, 1999-2001). The Shandong portion of this study was supported financially, in part, by the National Natural Science Foundation of China grant no. 40972005 to Rihui Li. The Nei Mongol portion of this study was supported by a grant from the National Natural Science Foundation of China (40872005) to Jianjun $\mathrm{Li}$ and the Beijing Museum of Natural History, with supplemental support from the Dinosaur Tracks Museum, University of Colorado Denver.We also thank Dr. Fei Hongcai (Editor of Acta Geologica Sinica) and the reviewers of this manuscript for their work and suggestions.

Manuscript received March 2, 2012 accepted Nov. 9, 2012 edited by Fei Hongcai

\section{References}

Chen, P.-J., Li, J., Matsukawa, M., Zhang, H., Wang, Q., and Lockley, M.G., 2006. Geological ages of dinosaur-track- 
bearing formations in China. Cretaceous Research, 27(1): 22 32.

Chen, S., and Huang, X., 1993. Preliminary study of dinosaur tracks in Cangling, Chuxiong Prefecture. Yunnan Geology, 12 (3): 267-276 (in Chinese with English abstract).

Currie, P.J., 1981. Bird footprints from the Gething Formation (Aptian, Lower Cretaceous) of northeastern British Columbia, Canada. Journal of Vertebrate Paleontology, 1(3-4): 257264.

Dong, Z.-M., Zhou, Z.-L., and Wu, S.-Y., 2003. Note on a hadrosaur footprint from Heilongiiang River area of China. Vertebrata PalAsiatica, 41(4): 324-326 (in Chinese with English abstract).

Ellenberger, P., 1972. Contribution à la classification des pistes de vertébrés du Trias: les types du Stormberg d'Afrique du Sud (I). Palaeovertebrata, Mémoire Extraordinaire: 1-111.

Gao, Y.-H., 2008. New dinosaur footprint from Lower Jurassic of Weiyuan, Sichuan. Vertebrata PalAsiatica, 45(4): 342-345 (in Chinese with English abstract).

Gierliński, G., 1994. Early Jurassic theropod tracks with the metatarsal impressions. Przeglad Geologiczny, 42(4): 280284.

Gierliński, G., Lockley, M.G., and Niedźiedzki, G., 2009. A distinctive crouching theropod trace from the Lower Jurassic of Poland. In: Pieńkowski, G., Martin, A.J., and Meyer, C.A. (eds.), Second International Congress on Ichnology (Ichnia 2008). Geological Quarterly, 53(4): 471-476

Hitchcock, E., 1858. Ichnology of New England: a Report on the Sandstone of the Connecticut Valley, Especially its Fossil Footmarks. Boston: William White, 220 (Reprinted 1974 by Arno Press, New York).

Jin, Y., and Yan, H., 1994. Bird footprints discovered in the Cretaceous red bed of the Gunpey Basin, Anhui. Geology of Anhui, 4(3): 57-61 (in Chinese with English abstract).

Kim, B.K., 1969. A study of several sole marks in the Haman Formation. Journal of the Geological Society of Korea, 5(4): 243-258.

Kuhn, O., 1958. Die Fährten der vorzeitlichen Amphibien und Reptilien. Bamberg: Verlagshaus Meisenbach KG, 64.

Li, J., Bai, Z., Lockley, M., Zhou, B., Liu, J., and Song, Y., 2010. Dinosaur tracks in Wulatezhongqi, Inner Mongolia. Acta Geologica Sinica, 84(5): 723-742 (in Chinese with English abstract).

Li, J., Bai, Z., and Wei, Q., 2011 On the dinosaur tracks from the Lower Cretaceous of Otog Qi, Inner Mongolia. Beijing: Geological Publishing House, 109.

Li, J., Lockley, M.G., Zhang, Y.G., Hu, S.M., Matsukawa, M., and Bai Z.Q., 2012. An important ornithischian tracksite in the Early Jurassic of the Shenmu Region, Shaanxi, China. Acta Geologica Sinica (English Edition), 86: 1-10

Li, J.-J., Bater, M., Zhang, W.-H., Hu, B.-L., and Gao, L.-H., 2006. A new type of dinosaur tracks from Lower Cretaceous Otog Qi, Inner Mongolia. Acta Palaeontologica Sinica, 45(2): 221-234 (in Chinese with English summary).

Li, R., Liu, M., and Matsukawa, M., 2002. Discovery of fossilized tracks of Jurassic dinosaur in Shandong. Geological Bulletin of China, 21(8-9): 596-597 (in Chinese).

Li, R., Lockley, M.G., and Liu, M., 2005.A new ichnotaxon of fossil bird track from the Early Cretaceous Tianjialou Formation (Barremian-Albian), Shandong Province, China. Chinese Science Bulletin, 50(11): 1149-1154.
Li, R., Lockley, M.G., Makovicky, P.J., Matsukawa, M., Norell, M.A., Harris, J.D., and Liu, M., 2008. Behavioral and faunal implications of Early Cretaceous deinonychosaur trackways from China. Naturwissenschaften, 95(3): 185-191.

Li, R., Lockley, M.G., Matsukawa, M., Wang, K., and Liu, M., 2011. An unusual theropod track assemblage from the Cretaceous of the Zhucheng area, Shandong Province, China.Cretaceous Research, 32(4): 422-432.

Li, R., and Zhang, G., 2000. New dinosaur ichnotaxon from the Early Cretaceous Laiyang Group in the Laiyang Basin, Shandong Province. Geological Review, 46(6): 605-610 (in Chinese with English summary).

Lockley, M.G., 1987. Dinosaur Footprints from the Dakota Group of Eastern Colorado, Mountain Geologist, 24: 107122.

Lockley, M.G., 2010. A solution to the Mehliella mystery: tracking, naming, identifying and measuring the first crocodylian trackway reported from the Cretaceous (Dakota Group, Colorado). In: Milàn, J., Lucas, S.G., and Spielmann, J.A. (eds.), Crocodyle Tracks and Traces. New Mexico Museum of Natural History and Science, Bulletin, 51: 157164.

Lockley, M., Cart, K., Martin, J., and Milner, A.R.C., 2011 b. New theropod tracksites from the Upper Cretaceous "Mesaverde" Group, western Colorado: implications for ornithomimosaur track morphology. In: Sullivan, R.M., Lucas, S.G., and Spielmann, J.A. (eds.), Fossil Record 3. New Mexico Museum of Natural History and Science Bulletin, 53: 321-329.

Lockley, M.G., Gierlinski, G.D., and Lucas, S.G., 2011 a. Kayentapus revisited: notes on the type material and the importance of this theropod footprint ichnogenus. In: Sullivan, R.M., Lucas, S.G., and Spielmann, J.A. (eds.), Fossil Record 3. New Mexico Museum of Natural History and Science Bulletin, 53: 330-336.

Lockley, M.G., and Gillette, D.D., 1989. Dinosaur tracks and traces: an overview. In: Gillette, D.D., and Lockley, M.G. (eds.), Dinosaur Tracks and Traces. Cambridge: Cambridge University Press, 3-10.

Lockley, M.G., and Harris, J.D., 2010. On the trail of early birds: a review of the fossil footprint record of avian morphological and behavioral evolution. In: Ulrich, P.K. and Willett, J.H. (eds.), Trends in Ornithology Research. Hauppauge: Nova Publishers, 1-63.

Lockley, M.G., and Harris, J.D., In press. Pterosaur trace fossils. In: Martill, D.M., Unwin, D., and Loveridge, R. (eds.), The Pterosauria. Cambridge: Cambridge University Press.

Lockley, M.G., Li, R., Harris, J.D., Matsukawa, M., and Liu, M. 2007. Earliest zygodactyl bird feet: evidence from Early Cretaceous roadrunner-like tracks. Naturwissenschaften, 94 (8): 657-665.

Lockley, M.G., Hook, N., and Taylor, A., 2001. A brief history of paleontological research and public education on dinosaur ridge. In: Lockley, M.G., and Taylor, A. (eds), Dinosaur Ridge: Celebrating a Decade of Discovery. Mountain Geologist, 38: 87-9.

Lockley, M., and Hunt, A.P., 1995. Dinosaur Tracks and Other Fossil Footprints of the Western United States. New York: Columbia University Press, 338.

Lockley, M.G., Kim, J.Y., Kim, K.S., Kim, S.H., Matsukawa, M., Li, R., Li, J., and Yang, S.-Y. 2008. Minisauripus-the 
track of a diminutive dinosaur from the Cretaceous of China and South Korea: implications for stratigraphic correlation and theropod foot morphodynamics. Cretaceous Research, 29 (1): $115-130$.

Lockley, M., Li, J., Matsukawa, M., and Li, R, 2012. A new avian ichnotaxon from the Cretaceous of Nei Mongol, China.Cretaceous Research, 34: 84-93.

Lockley, M.G., Li, R., Matsukawa, M., and Li, J. 2010. Tracking Chinese crocodylians: Kuangyuanpus, Laiyangpus, and implications for naming crocodylian and crocodylian-like tracks and associated ichnofacies. In: Milàn, J., Lucas, S.G., Lockley, M.G., and Spielmann, J.A. (eds.), Crocodyle Tracks and Traces. New Mexico Museum of Natural History and Science Bulletin, 51: 99-108.

Lockley, M.G., and Matsukawa, M. 2009. A review of vertebrate track distributions in east and southeast Asia. Journal of the Paleontological Society of Korea, 25(1): 17-42.

Lockley, M., Matsukawa, M., and Li, J., 2003. Crouching theropods in taxonomic jungles: ichnological and ichnotaxonomic investigations of footprints with metatarsal and ischial impressions. In: Pemberton, S.G., McCrea, R.T., and Lockley, M.G. (eds.), William Antony Swithin Sarjeant (1935-2002): A Celebration of His Life and Ichnological Contributions Volume 1. Ichnos, 10: 169-177.

Lockley, M., Matsukawa, M., Ohira, H., Li, J., Wright, J., White, D., and Chen, P., 2006. Bird tracks from Liaoning Province, China: new insights into avian evolution during the JurassicCretaceous transition. Cretaceous Research, 27(1): 33-43.

Lockley, M.G., Meyer, C.A., and Moratalla, J.J., 2000. Therangospodus: trackway evidence for the widespread distribution of a Late Jurassic theropod with well-padded feet. In: Pérez-Moreno, B.P., Holtz, T., Sanz, J.L., and Moratalla, J.J. (eds.), Aspects of Theropod Paleobiology. Gaia, 15: 339353.

Lockley, M.G., Nadon, G., and Currie, P.J., 2004. A diverse dinosaur-bird footprint assemblage from the Lance Formation, Upper Cretaceous, eastern Wyoming: implications for ichnotaxonomy. Ichnos, 11: 229-249.

Lockley, M., Wright, J., White, D., Matsukawa, M., Li, J., Feng, L., and $\mathrm{Li}, \mathrm{H}$., 2002. The first sauropod trackways from China. Cretaceous Research, 23(3): 363-381.

Lockley, M.G., Yang, S.Y., Matsukawa, M., Fleming, F., and Lim, S.K., 1992. The track record of Mesozoic birds: evidence and implications. Philosophical Transactions of the Royal Society of London B, 336: 113-134.

Lil, H., Zhang, Y., and Xiao, J., 2004. Chirotherium: fossil footprints of primitive reptiles in the Middle Triassic Guanling Formation, Zhenfeng, Guizhou Province, China. Acta Geologica Sinica, 78(4): 468-474 (in Chinese with English abstract).

Lü, J., Azuma, Y., Wang, T., Li, S., and Pan, S., 2006. The first discovery of dinosaur footprint from Lufeng of Yunnan Province, China. Memoir of the Fukui Prefectural Museum, 5: 35-39.

Lil, J., Zhang, X., Jia, S., Hu, W., Wu, Y., and Ji, Q., 2007.The discovery of theropod dinosaur footprints from the Middle Jurassic Yima Formation of Yima County, Henan Province. Acta Geologica Sinica, 81(4): 439-444 (in Chinese with English abstract).

Lucas, S.G., 2007. Tetrapod footprint biostratigraphy and biochronology. Ichnos, 14(1): 5-38.
Lucas, S.G., Klein, H., Lockley, M.G., Spielmann, J.A., Gierliński, G.D., Hunt, A.P., and Tanner, L.H., 2006. Triassic-Jurassic stratigraphic distribution of the theropod footprint ichnogenus Eubrontes. In: Harris, J.D., Lucas, S.G., Spielmann, J.A., Lockley, M.G., Milner, A.R.C., and Kirkland, J.I. (eds.), The Triassic-Jurassic Terrestrial Transition. New Mexico Museum of Natural History and Science Bulletin, 37: 86-93.

Lull, R.S., 1904. Fossil footprints of the Jura-Trias of North America.Memoirs of the Boston Society of Natural History, 5: 461-557.

Lull, R.S., 1953. Triassic Life of the Connecticut Valley Revised. State of Connecticut State Geological and Natural History Survey, 81: 1-336.

Matsukawa, M., Lockley, M., and Li, J., 2006. Cretaceous terrestrial biotas of East Asia, with special reference to dinosaur-dominated ichnofaunas: towards a synthesis. Cretaceous Research, 27(1): 3-21.

Matsukawa, M., Shibata, K., Kukihara, R., Koarai, K., and Lockley, M.G., 2005. Review of Japanese dinosaur track localities: implications for ichnotaxonomy, paleogeography and stratigraphic correlation. Ichnos, 12(3): 201-222.

Olsen, P.E., 1980. Fossil great lakes of the Newark Supergroup in New Jersey. In: Manspeizer, W. (ed.), Field Studies of New Jersey Geology and Guide to Field Trips 52nd Annual Meeting of the New York State Geological Association. Staten Island: New York State Geological Association, 352-398.

Olsen, P.E., and Galton, P.M., 1984. A review of the reptile and amphibian assemblages from the Stormberg of southern Africa, with special emphasis on the footprints and the age of the Stormberg. Palaeontologia Africana, 25: 87-110.

Olsen, P.E., Smith, J.B., and McDonald, N.G., 1998. Type material of the type species of the classic theropod footprint genera Eubrontes, Anchisauripus, and Grallator (Early Jurassic, Hartford and Deerfield basins, Connecticut and Massachusetts, U.S.A.). Journal of Vertebrate Paleontology, 18(3): 586-601.

Peng, B.-X., Du, Y.-S., Li, D.-Q., and Bai, Z.-C., 2004. The first discovery of the Early Cretaceous pterosaur track and its significance in Yanguoxia, Yongjing County, Gansu Province. Journal of China University of Geosciences (Earth Science), 29(1): 21-24 (in Chinese).

Rainforth, E.C., 2005. Ichnotaxonomy of the Fossil Footprints of the Connecticut Valley (Early Jurassic, Newark Supergroup, Connecticut and Massachusetts) [Ph.D. dissertation]: New York, Columbia University, 1301.

Sarjeant, W.A.S., 1989. Ten paleoichnological commandments: a standardized procedure for the description of fossil vertebrate footprints. In: Gillette, D.D., and Lockley, M.G., (eds) Dinosaur Tracks and Traces. Cambridge: Cambridge University Press, 369-370

Sarjeant, W.A.S., Delair, J.B., and Lockley, M.G., 1998. The footprints of Iguanodon: a history and taxonomic study. Ichnos, 6(3): 183-202.

Sullivan, C., Hone, D.W.E., Cope, T.D., Liu, Y., and Liu, J., 2009. A new occurrence of small theropod tracks in the Houcheng (Tuchengzi) Formation of Hebei Province, China. Vertebrata PalAsiatica, 47(1): 35-52.

Teilhard de Chardin, P., and Young, C.C., 1929. On some traces of vertebrate life in the Jurassic and Triassic beds of Shansi and Shensi. Bulletin of the Geological Society of China, 8: 
131-133.

Thulborn, R.A. 1990. Dinosaur tracks. Chapman Hall, 410.

Wang, S.N., 2012. Dinosaur tracks on the cliff, the great dinosaur discoveries in Qijiang, Chongqing Municipality, China. National Geographic (Simplified Chinese Version). 138-151.

Welles, S.P., 1971. Dinosaur footprints from the Kayenta Formation of northem Arizona. Plateau, 44: 27-38.

Xing, L., Harris, J.D., and Gierliński, G., 2011a. Therangospodus and Megalosauripus track assemblage from the Upper Jurassic-Lower Cretaceous Tuchengzi Formation of Chicheng County, Hebei Province, China and their paleoecological implications. Vertebrata PalAsiatica, 49(4): 423-434.

Xing, L.-D., Harris, J.D., Jia, C.-K., Luo, Z.-J., Wang, S.-N., and An, J.-F., 2011b. Early Cretaceous bird-dominated and dinosaur footprint assemblage from the northwestern border of the Junggar Basin, Xinjiang, China. Palaeoworld, 20(4): 308-321.

Xing, L.-D., Harris, J.D., Wang, K.-B., and Li, R.-H., 2010. An Early Cretaceous non-avian dinosaur and bird footprint assemblage from the Laiyang Group in the Zhucheng basin, Shandong Province, China. Geological Bulletin of China, 29 (8): 1105-1112.

Xing., L., Bell, P., Harris, J.D., and Currie, P.J., 2012. An unusual, three-dimensionally preserved, large hadrosauriform pes track from "mid"-Cretaceous Jiaguan Formation of Chongqing, China. Acta Geologica Sinica (English Edition), 86: 304-312.

Xing, L., Harris, J.D., Toru, S., Masato, F., and Dong, Z.-M., 2009a. Discovery of dinosaur footprints from the Lower Jurassic Lufeng Formation of Yunnan Province, China and new observations on Changpeipus. Geological Bulletin of China, 28(1): 16-29.

Xing, L.-D., Harris, J.D., Sun, D.-H., and Zhao, H.-Q. 2009b. The earliest known deinonychosaur tracks from the JurassicCretaceous boundary in Hebei Province, China. Acta Palaeontologica Sinica, 48(4): 662-671.

Xing, L.-D., Harris, J.D., Dong, Z.-M., Lin, Y.-L., Chen, W., Guo, S.-B., and Ji, Q., 2009c. Ornithopod (Dinosauria: Ornithischia) tracks from the Upper Cretaceous Zhutian Formation in the Nanxiong Basin, Guangdong, China and general observation on large Chinese ornithopod footprints. Geological Bulletin of China, 28(7): 829-843.

Xing, L.-D., Li, D., Harris, J.D., Bell, P.R, Azuma, Y., Fujita, M., Lee, Y.-N., and Currie, P.J., 2012. A new Dromaeosauripus (Dinosauria: Theropoda) ichnospecies from the Lower Cretaceous Hekou Group, Gansu Province, China. Acta Paleontological Polonica. doi: 10.4202/app.2011.0115

Xing, L.D, Lockley, M.G., Chen, W., Gierliński, G.D., Li, J.J.,
Persons, W.S., IV, Matsukawa, M., Ye, Y., Gingras, M.K., and Wang, C.W., in press. Two theropod track assemblages from the Jurassic of Chongqing, China, and the Jurassic Stratigraphy of Sichuan Basin. Vertebrata Palasiatica.

Xing, L., Wang, F., Pan, S., and Chen, W., 2007. The discovery of dinosaur footprints from the Middle Cretaceous Jiaguan Formation of Qijiang County, Chongqing City. Acta Geologica Sinica, 81(11): 1591-1602 (in Chinese with English abstract).

Yabe, H., Inai, Y., and Shikama, T., 1940. Discovery of dinosaurian footprints from the Cretaceous (?) of Yangshan, Chinchou. Preliminary note. Proceedings of the Imperial Academy (of Japan), 16(10): 560-563.

Yang, X., and Yang, D., 1987. Dinosaur Footprints from Mesozoic of Sichuan Basin. Chengdu City: Science and Technology Publications, 30 (in Chinese).

Young, C.-C., 1943. Note on some fossil footprints in China. Bulletin of the Geological Society of China, 13(3-4): 151154.

Young, C.-C., 1960. Fossil footprints in China. Vertebrata PalAsiatica, 4(2): 53-67.

Young, C.C., 1966. Two footprints from the Jiaoping Coal Mine of Tungchuan, Shensi. Vertebrata PalAsiatica, 10(1): 68-71 (in Chinese with English summary).

Young, C.C., 1979. Footprints from Jinghong, Yunnan. Vertebrata PalAsiatica, 17(2): 116-117 (in Chinese with English summary).

Zeng, X.Y., 1982a. Dinosaur footprints found in red beds of the Yuan Ma Basin, west of Hunan, Xingxi. Hunan Geology, 1: 57-58 (in Chinese).

Zeng, X., 1982b. Fossil Handbook of Hunan Province. Geology Bureau of Hunan Province, 45 (in Chinese).

Zhen, S., Li, J., Han, Z., and Yang, X., 1996. The Study of Dinosaur Footprints in China. Chengdu: Sichuan Scientific and Technological Publishing House, 110 (in Chinese with English abstract).

Zhen, S., Li, J., and Rao, C., 1986. Dinosaur footprints of Jinning, Yunnan. Memoirs of the Beijing Natural History Museum, 33(5): 1-19.

Zhen, S., Li, J., Rao, C., Mateer, N.J., and Lockley, M.G., 1989. A review of dinosaur footprints in China. In: Gillette, D.D., and Lockley, M.G. (eds.), Dinosaur Tracks and Traces. Cambridge: Cambridge University Press, 187-197.

Zhen, S., Li, J., and Zhang, B., 1994. Dinosaur and bird footprints from the Lower Cretaceous of Emei County, Sichuan, China. Memoirs of the Beijing Natural History Museum, 54: 105-120.

Zhen, S., Li, J., and Zhen, B., 1983.Dinosaur footprints of Yuechi, Sichuan. Memoirs of the Beijing Natural History Museum, 25: 1-19. 